\title{
Synaptic Transmission and Plasticity at Inputs to Murine Cerebellar Purkinje Cells Are Largely Dispensable for Standard Nonmotor Tasks
}

\author{
Elisa Galliano, ${ }^{1}$ Jan-Willem Potters, ${ }^{1}$ Ype Elgersma, ${ }^{1,2}$ William Wisden, ${ }^{4}$ Steven A. Kushner, ${ }^{3}$ Chris I. De Zeeuw, ${ }^{1,5}$ \\ and Freek E. Hoebeek ${ }^{1}$ \\ ${ }^{1}$ Department of Neuroscience, ${ }^{2}$ ENCORE Expertise Center for Neurodevelopmental Disorders, and ${ }^{3}$ Department of Psychiatry, Erasmus Medical Centre, \\ 3015 GE Rotterdam, The Netherlands, ${ }^{4}$ Department of Life Sciences, Imperial College London, London SW7 2AZ, United Kingdom, and ${ }^{5}$ Netherlands \\ Institute for Neuroscience, Royal Netherlands Academy of Arts and Sciences, 1105 BA Amsterdam, The Netherlands
}

In addition to its well established role in motor coordination, the cerebellum has been hypothesized to be involved in the control of cognitive and emotional functions. Although a cerebellar contribution to nonmotor functions has been supported by recent studies in human and monkey, it remains to be clarified with an in-depth, systematic approach in mouse mutants. Here we subjected four different cerebellar cell-specific mouse lines whereby the excitatory or inhibitory input to Purkinje cells (PCs) and/or PC postsynaptic plasticity were compromised, to a wide battery of standard cognitive and emotional tests. The four lines, which have all been shown to suffer from impaired motor learning without being ataxic, were tested for social behavior using a sociability task, for spatial navigation using the Morris watermaze, for fear responses using contextual and cued conditioning, and general anxiety using the open-field task. None of the four cerebellum-specific genetic perturbations showed significantly impaired cognitive or emotional behavior. In fact, even without correction for multiple comparisons, only 5 of 154 statistical comparisons showed a marginally significant deficit. Therefore, our data indicate that none of the perturbations of cerebellar functioning studied here affected the cognitive or emotional tests we used. This suggests that there may be a differential impact of the murine and human cerebellum on nonmotor functions. We hypothesize that these differences could be a consequence of the remarkable enlargement of the cerebellar hemispheres during the latest phase of vertebrate phylogeny, which occurred in parallel with the evolution of the cerebral cortex.

\section{Introduction}

Since the end of the 19th century, when Flourens' physiological experiments dismissed the phrenological idea that the cerebellum was the seat of reproductive drive, the cerebellum has been thought to control purely motor functions (Glickstein et al., 2009). Yet in recent years, a novel body of evidence has emerged, reopening the debate on the actual role of the cerebellum. This new evidence was mainly obtained in human and nonhuman primates on the basis of neuropsychological studies in cerebellar patients, functional imaging studies in human subjects, and trac-

\footnotetext{
Received April 18, 2013; revised June 13, 2013; accepted June 20, 2013.

Author contributions: E.G., Y.E., S.A.K., C.I.D.Z., and F.E.H. designed research; E.G. performed research; W.W. contributed unpublished reagents/analytic tools; E.G. and J.-W.P. analyzed data; E.G., C.I.D.Z., and F.E.H. wrote the paper.

This work was supported by the Dutch Organization for Medical Sciences (ZonMw; F.E.H., C.I.D.Z., S.A.K., Y.E.), Life Sciences (ALW; F.E.H., C.I.D.Z.), Erasmus University Fellowship (F.E.H.), Senter (Neuro-Basic; C.I.D.Z., Y.E.), ERC-adv, CEREBNET (C.I.D.Z.), and C7 programs of the European Community (S.A.K., C.I.D.Z.). We are grateful to C. Bruinsma, K. Achterberg, and all the members of the Elgersma and Kushner Laboratories for technical assistance, and to M. Schonewille, B.J. van Beugen, and Z. Gao for critical discussions.

The authors declare no competing financial interests.

Correspondence should be addressed to Chris I. De Zeeuw, Department of Neuroscience, Erasmus MC, Dr. Molewaterplein 50, 3015GE Rotterdam, The Netherlands. E-mail: c.dezeeuw@erasmusmc.nl.

DOI:10.1523/JNEUROSCI.1642-13.2013

Copyright $\odot 2013$ the authors $\quad 0270-6474 / 13 / 3312599-20 \$ 15.00 / 0$
}

ing experiments in monkeys (Strick et al., 2009; Schmahmann, 2010; Timmann et al., 2010). Remarkably, all three lines of research strongly suggest that the cerebellum is involved not only in motor control, but also in emotional and cognitive processing. Thus far, only a limited set of studies has been dedicated to elucidate the contribution of the cerebellum to nonmotor functions in mice, and these studies were restricted to highly specific aspects of spatial navigation (Burguière et al., 2005; Rochefort et al., 2011) and/or are difficult to interpret because of concomitant ataxia or the use of global, i.e., noncerebellum-specific, mutations (Lalonde and Strazielle, 2003; Sacchetti et al., 2004).

To take a more systematic approach in overcoming potential confounding caveats, we selected four non-ataxic, cerebellar cellspecific mouse lines that suffer from compromised motor learning due to altered functioning of the Purkinje cell (PC), i.e., the final and principal station of cerebellar cortical computation (Gao et al., 2012), and we subjected them to a wide variety of tasks that challenge cognitive and/or emotional processing. In two mouse lines, basic neurotransmission onto PCs was impaired: the $\alpha 6$-Cacnala KO, in which PCs lost $70-80 \%$ of their excitatory input from granule cells (referred to as "less-excit"; see Fig. 1; Galliano et al., 2013), and the L7- $\gamma 2$, in which PCs receive no synaptic inhibitory input from molecular layer interneurons (re- 


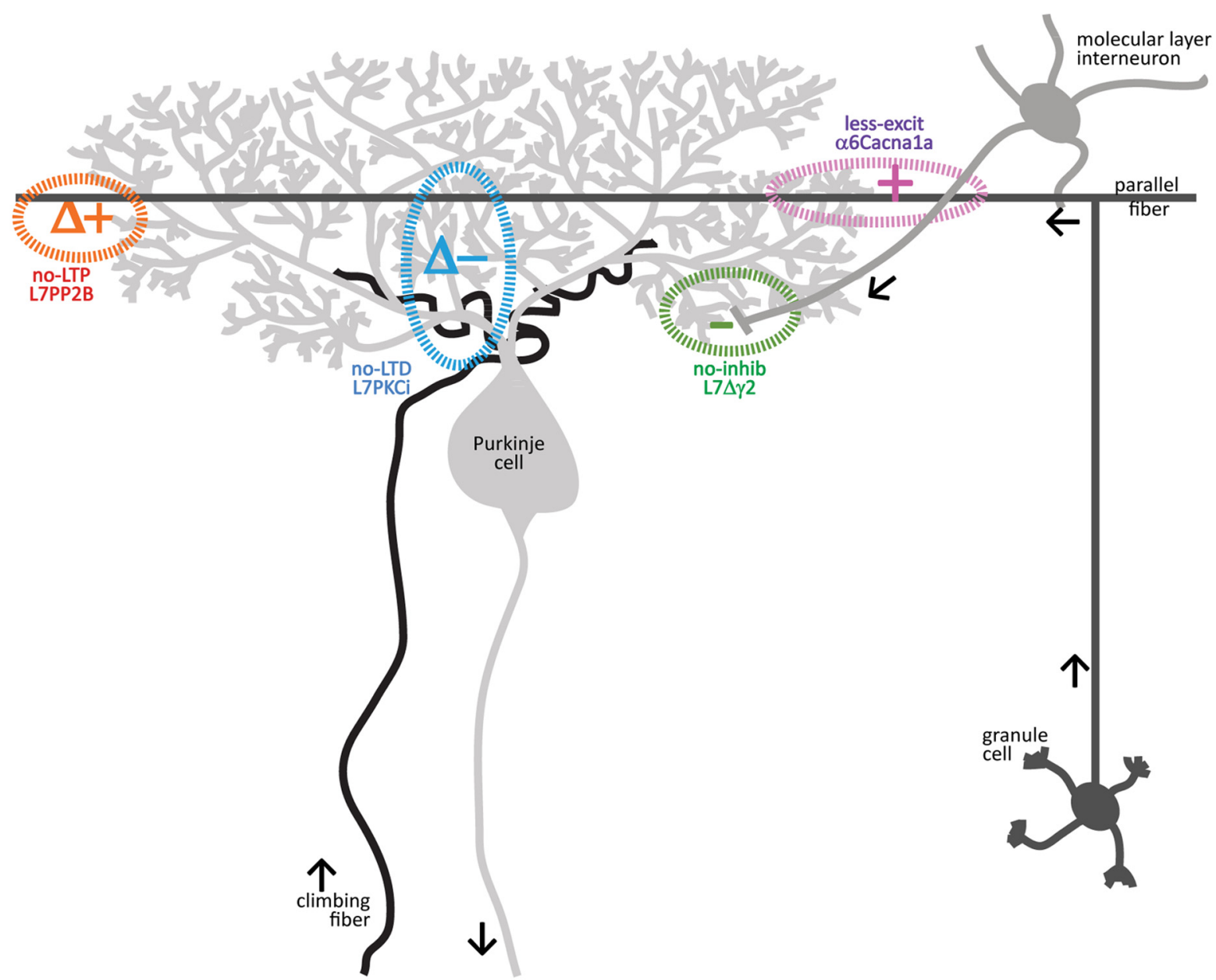

\begin{tabular}{|c|c|c|c|c|c|c|}
\hline & name & reference & abbrev. & impairment & sensory functions & motor functions \\
\hline \multirow{2}{*}{ 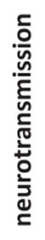 } & $\begin{array}{c}\alpha 6- \\
\text { Cacna1a KO }\end{array}$ & $\begin{array}{l}\text { Galliano et al, } \\
\quad 2013\end{array}$ & less-excit & $\begin{array}{l}\text { minimized neurotransmission } \\
\text { between } \mathrm{PF} \text { and } \mathrm{PC} / \mathrm{MLI}\end{array}$ & $\begin{array}{l}\text { vision: } \checkmark \\
\text { hearing: } \checkmark \\
\text { smell: } \checkmark\end{array}$ & $\begin{array}{l}\text { locomotion/coordination: } \checkmark \\
\text { eye movements: } \checkmark \\
\text { motor learning: - - }\end{array}$ \\
\hline & $\begin{array}{l}\text { L7- } \\
\gamma 2 \mathrm{KO}\end{array}$ & $\begin{array}{l}\text { Wulff et al, } \\
2009\end{array}$ & no-inhib & $\begin{array}{l}\text { absent neurotransmission } \\
\text { between } \mathrm{MLI} \text { and PC }\end{array}$ & $\begin{array}{l}\text { vision: } \checkmark \\
\text { hearing: } \checkmark \\
\text { smell: } \checkmark\end{array}$ & $\begin{array}{l}\text { locomotion/coordination: } \checkmark \\
\text { eye movements: - } \\
\text { motor learning: - - }\end{array}$ \\
\hline \multirow{2}{*}{ 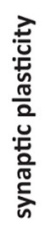 } & $\begin{array}{c}\text { L7- } \\
\text { PP2B KO }\end{array}$ & $\begin{array}{l}\text { Schonewille et al, } \\
\quad 2010\end{array}$ & $\stackrel{\bullet}{\text { no-LTP }}$ & $\begin{array}{c}\text { absent PF-PC } \\
\text { long term potentiation }\end{array}$ & $\begin{array}{l}\text { vision: } \checkmark \\
\text { hearing: } \checkmark \\
\text { smell: } \checkmark\end{array}$ & $\begin{array}{l}\text { locomotion/coordination: } \checkmark / \text { - } \\
\text { eye movements: - - } \\
\text { motor learning: - - }\end{array}$ \\
\hline & $\begin{array}{l}\text { L7- } \\
\text { PKCi Tg }\end{array}$ & $\begin{array}{l}\text { De Zeeuw et al, } \\
1998\end{array}$ & $\stackrel{\bigcirc}{\text { no-LTD }}$ & $\begin{array}{c}\text { absent PF-PC } \\
\text { long term depression }\end{array}$ & $\begin{array}{l}\text { vision: } \checkmark \\
\text { hearing: } \checkmark \\
\text { smell: } \checkmark\end{array}$ & $\begin{array}{l}\text { locomotion/coordination: } \checkmark \\
\text { eye movements: } \checkmark \\
\text { motor learning: - - }\end{array}$ \\
\hline
\end{tabular}

Figure 1. Characteristics of the four genetically modified mouse lines. Top, Schematic representation of the cerebellar cortical circuit and the four different cell-specific manipulations. Bottom, Summary table indicating the full names and literature reference to the original descriptive papers of the four main mouse lines, the abbreviated name used in this study, their main cellular phenotype, and an overview of their motor and sensory characteristics as studied in the original manuscripts. No deficits, V; minor deficits, -; moderate deficits, - -; severe deficits, - - -

ferred to as "no-inhib"; Wulff et al., 2009). The other two mouse lines lacked the ability to strengthen or weaken their parallel fiber (PF)-PC synapses: the L7-PP2B KO mice, which show no intrinsic plasticity or PF-PC long-term potentiation (referred to as "no-LTP"; Schonewille et al., 2010), and the L7-PKCI TG line, which has no PF-PC long-term depression (referred to as "noLTD"; De Zeeuw et al., 1998). Notably, all of these mice have been shown to suffer from impaired motor learning and/or consolidation in that they have deficits in adaptation of the vestibulo-ocular reflex, eyeblink conditioning, and/or locomotion conditioning on the Erasmus ladder (De Zeeuw et al., 2011). With regard to the behavioral tests for cognition and emotion used in the present study, we focused on well validated tasks for social behavior, spatial navigation, fear conditioning, and general 


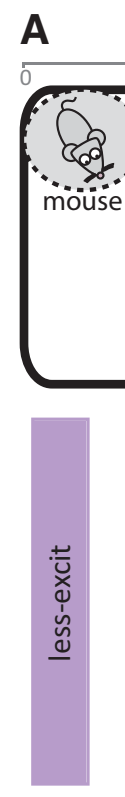

Sociability
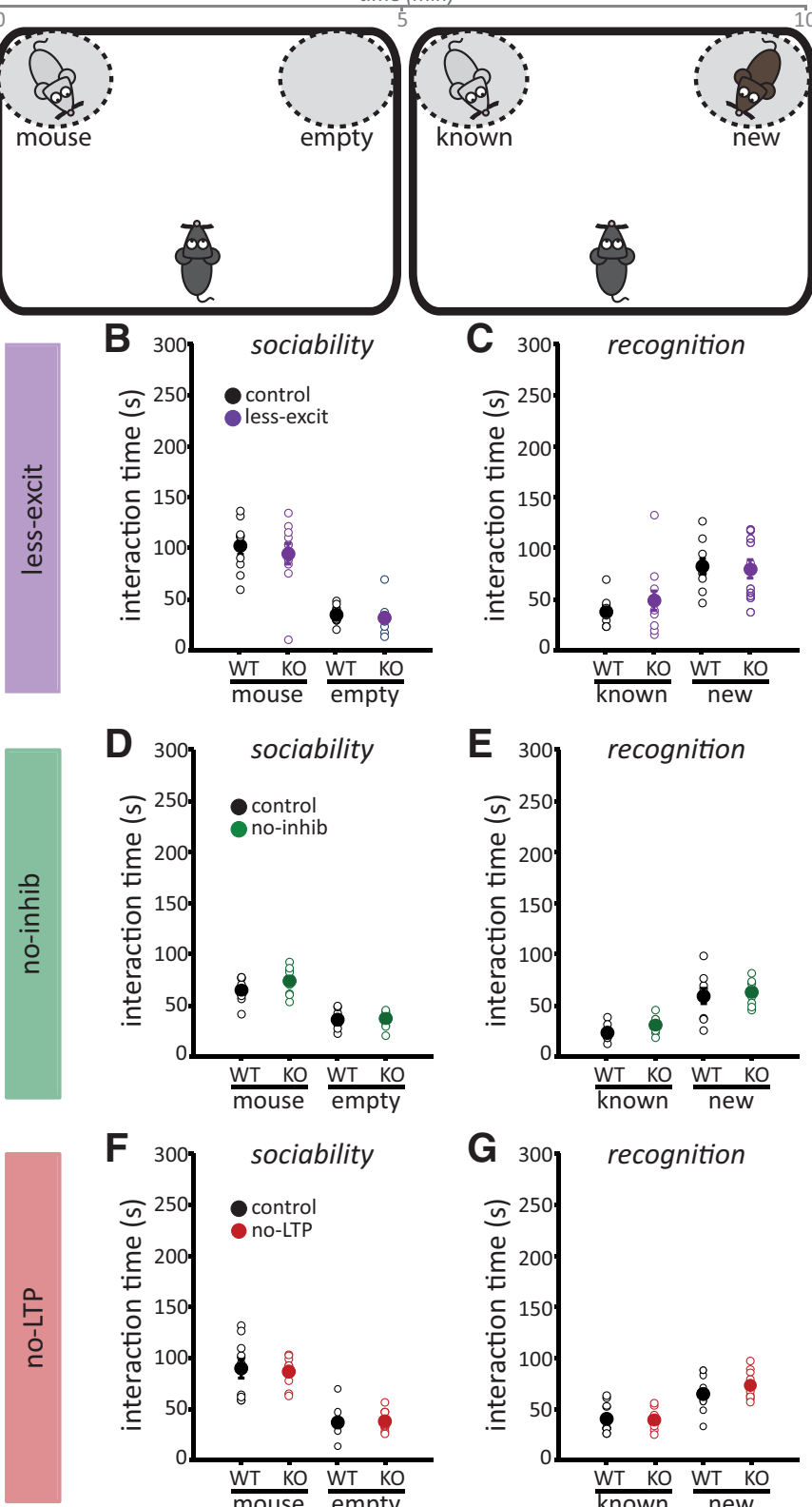

\section{$F$}
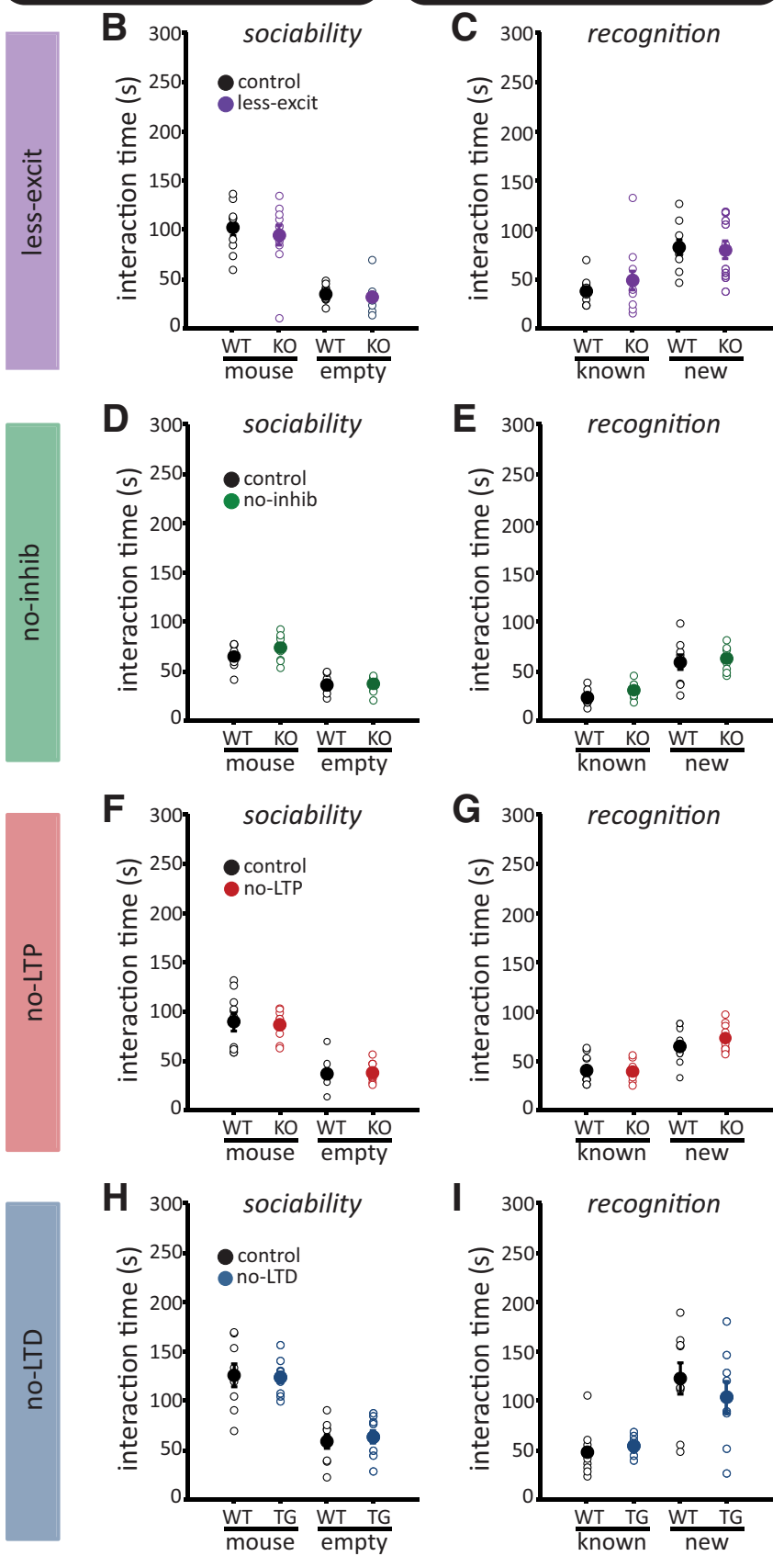

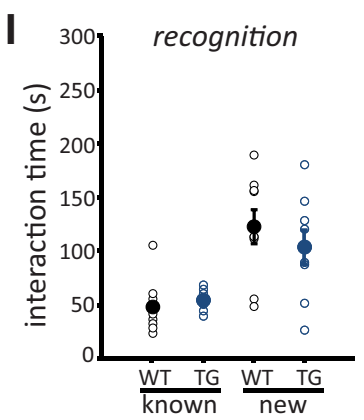

J Olfactory function
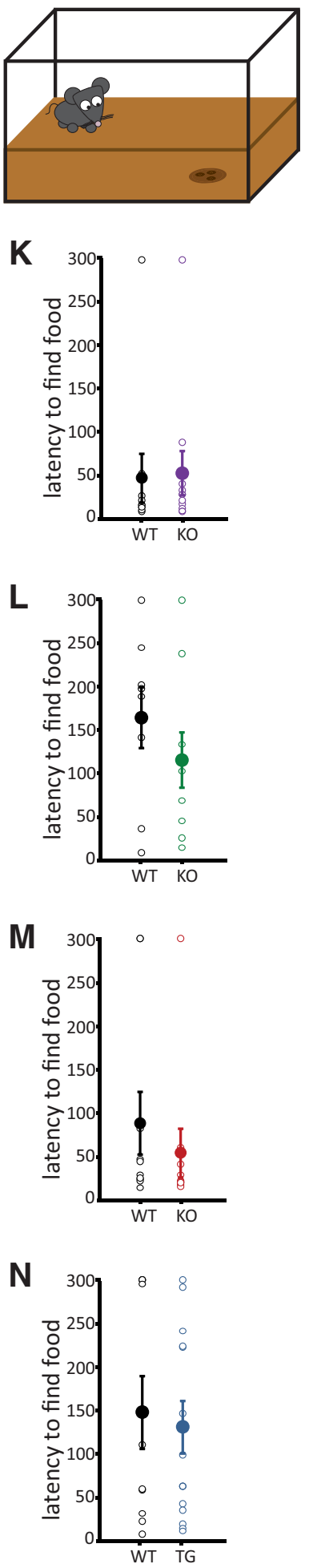

Figure 2. Social behavior. $\boldsymbol{A}$,Graphical representation of the social behavior task. In the sociability phase mice were allowed to walk freely for 5 min in a rectangular arena containing two subcompartments, one empty and one hosting an unknown mouse (Stranger 1). Subsequently, with no delay, the Social recognition phase (5 min long) started: a second unknown mouse (Stranger 2) was places in the empty compartment. The time spent by the test mouse sniffing the two compartments was measured. $\boldsymbol{B}$, Time spent by $\alpha 6$-Cacna1a mice (less-excit, $n=11$ ) and their control littermates ( $n=10$ ) investigating Stranger 1 and the empty compartment during the sociability phase. $C$, Time spent by the same $\alpha 6$-Cacna1a mice (K0 and Ctrl) investigating either Stranger 1 (known) or Stranger 2 (new) during the social recognition phase. $\boldsymbol{D}, \boldsymbol{E}$, Similar to $\boldsymbol{B}, \boldsymbol{C}$ for L7- $\gamma 2$ mice (no-inhib, $n=8)$ and their control littermates $(n=9)$. $\boldsymbol{F}, \boldsymbol{G}$, Similar to $\boldsymbol{B}, \boldsymbol{C}$ for L7-PP2B mice (no-LTP, $n=10)$ and their control littermates $(n=10)$. $\boldsymbol{H}$, $\boldsymbol{I}$, Similar to $\boldsymbol{B}, \boldsymbol{E}$ for L7-PKCimice (no-LTD, $n=9$ ) and their control littermates $(n=9)$.J, Graphical representation of buried food task. Mice were allowed 5 min to find and unbury the alimentary treat. $\boldsymbol{K}$, Latency to unbury the food of $\alpha 6$-Cacna1a mice (less-excit, $n=11)$ and their control littermates $(n=10)$. $\boldsymbol{L}-\boldsymbol{N}$, Similar to $\boldsymbol{K}$ for L7- $\gamma 2$ mice $(\boldsymbol{L} ; \mathrm{Ctrl}, n=8 ; n 0$-inhib, $n=8) \mathrm{L} 7$-PP2B mice $(\boldsymbol{M}$; Ctrl, $n=10 ;$ no-LTP, $n=$ 10) and L7-PKCi mice ( $N$; Ctrl, $n=10 ;$ no-LTD, $n=13)$. Open circles represent individual data points, filled circles are mean \pm SEM; $p$ values are indicated in the main text and Tables $1-2$. 
anxiety (Crawley, 2007; Buccafusco, 2009). Thus, we aimed to specifically examine the hypothesis that changes in either the synaptic input onto PCs, or postsynaptic plasticity thereof, might contribute to cognitive and/or emotional processing.

\section{Materials and Methods}

Animals

Three to 6-month-old mutant mice and their littermate controls of both sexes were analyzed in this study. The mutant lines used were as follows:

- Knock-out mice in which $70-80 \%$ of granule cells (GCs) are silent (called $\alpha 6$-Cacnala or here referred to as less-excit) due to the selective elimination of their P/Q-type $\mathrm{Ca}^{2+}$-channels, which mediate the bulk of neurotransmitter release at the PF-PC synapse (Galliano et al., 2013).

- Knock-out mice in which the synaptic transmission from molecular layer interneurons to PCs is blocked (called L7- $\gamma 2$ or here noinhib), an effect obtained by selectively ablating the $\gamma 2$ subunit of the GABA $_{A}$-receptors in PCs (Wulff et al., 2009). Part of the data obtained with L7- $\gamma 2$ mice were investigated for confirmation using mutants that lack synaptic transmission between molecular layer interneurons and $\mathrm{PCs}$ due to the absence of the $\mathrm{K}-\mathrm{Cl}$ cotransporters, KCC type 2 and 3 in PCs [called L7-KCC or here no-inhib(KCC); Seja et al., 2012].

- Knock-out mice with impaired long-term potentiation and intrinsic plasticity (called L7-PP2B or here no-LTP), in which the calcium/calmodulin-activated protein-phosphatase-2B is selectively impaired in PCs by crossing floxed CNB1 mice (regulatory subunit of calcineurin) with a Purkinje cell-specific (L7-)cre-line (Belmeguenai et al., 2010; Schonewille et al., 2010).

- Transgenic mice with impaired PF-PC long-term depression (called L7-PKCI or here no-LTD), in which the pseudosubstrate PKC inhibitor, PKC[19-31], is selectively expressed in PCs under the control of the $L 7$ promoter (De Zeeuw et al., 1998).

In the cell-specific Cre-loxP lines ( $\alpha 6$-Cacna1a, L7- $\gamma 2$, L7-KCC, L7$\mathrm{PP} 2 \mathrm{~B})$ the control groups included mice of the Cre-positive/loxP-Wt, Cre-negative/loxP-Wt, and Cre-negative/loxP-hom genotypes. The control group of the transgenic line L7-PKCI included Cre/PKCI-negative mice. For all lines controls and mutant groups were littermates, agematched and gender-matched. All animals were bred in a C57BL/6NHsd mouse strain background (Harlan) and littermates were group-housed in standard conditions (12 h light/dark cycles, light on at 7:00 A.M., and water and food ad libitum). After performing the open-field experiment, mice were handled for $2 \mathrm{~min}$ per day for 5 consecutive days. All data were obtained during the light phase and all experiments were in compliance with the Dutch ethical animal committee. Experiments and analysis were performed by the same researcher (E.G.) in blind conditions with respect to the genotype of the animals.

\section{Behavioral tests}

Sociability and social novelty preference. To test the social behavior, we used a rectangular, transparent box $(40 \times 25 \times 20 \mathrm{~cm})$ equipped with two removable circular metal cages with bars (diameter $9 \mathrm{~cm}$; see Fig. $2 A$ ); both the box and the two cages were covered with a thick Plexiglas roof which prevented the mice from escaping. The boxes and cages of the social apparatus were cleaned and fresh bedding sand was added for each animal, and the room lighting was dimmed to minimize anxiety. The test mouse was first placed in the box without the circular cages and allowed to explore for $15 \mathrm{~min}$. After the habituation period, the cages were put in place and an unfamiliar mouse (Stranger 1) that had no prior contact with the subject mouse was placed in one of the circular cages. The cages allowed nose contact through the bars, but prevented fighting and sexually oriented behavior. The test mouse was allowed to explore for a $5 \mathrm{~min}$ session. The experimenter manually measured how long the test mouse spent sniffing the cage behind which Stranger 1 was placed (mouse) and the one behind which no mouse was placed (empty). Occasionally the test mouse stood on top of the Plexiglas roof of the circular cages in an attempt to escape: this time was not quantified as interaction time. At the end of the first 5
Table 1. Social behavior quantification

\begin{tabular}{|c|c|c|c|}
\hline Less-excit ( $\alpha 6$ Cacna1a) & $\mathrm{WT}, n=10$ & $\mathrm{~K} 0, n=11$ & $\overline{M W / t \text { test }}$ \\
\hline Mouse (s) & $103 \pm 7.8$ & $95.1 \pm 9.9$ & 0.65 \\
\hline Empty (s) & $35.4 \pm 2.7$ & $32.5 \pm 4.4$ & 0.32 \\
\hline$M W / t$ test mouse versus empty & $<0.00$ & 0.00 & \\
\hline Known mouse (s) & $38.4 \pm 4.5$ & $42.5 \pm 9.8$ & 0.48 \\
\hline New mouse (s) & $82.9 \pm 7.4$ & $80.1 \pm 8.9$ & 0.81 \\
\hline$M W / t$ test known versus new & 0.00 & 0.02 & \\
\hline No-inhib (L7- $\gamma 2)$ & WT, $n=9$ & $\mathrm{~K} 0, n=8$ & $M W / t$ test \\
\hline Mouse (s) & $65.6 \pm 4.0$ & $74.5 \pm 5.1$ & 0.18 \\
\hline Empty (s) & $36.7 \pm 3.1$ & $37.9 \pm 3.3$ & 0.85 \\
\hline$M W / t$ test mouse versus empty & 0.00 & 0.00 & \\
\hline Known mouse (s) & $23.9 \pm 2.6$ & $31.4 \pm 3.0$ & 0.08 \\
\hline New mouse (s) & $59.7 \pm 7.6$ & $63.5 \pm 4.7$ & 0.68 \\
\hline$M W / t$ test known versus new & 0.00 & 0.00 & \\
\hline No-LTP (L7-PP2B) & $\mathrm{WT}, n=10$ & $\mathrm{~K} 0, n=10$ & $M W / t$ test \\
\hline Mouse (s) & $61.7 \pm 13.3$ & $59.5 \pm 15.1$ & 0.33 \\
\hline Empty (s) & $32.8 \pm 7.2$ & $30.2 \pm 7.9$ & 1.00 \\
\hline$M W / t$ test mouse versus empty & 0.00 & $<0.00$ & \\
\hline Known mouse (s) & $27.9 \pm 6.4$ & $25.2 \pm 6.2$ & 0.79 \\
\hline New mouse (s) & $52.9 \pm 12.1$ & $51.4 \pm 13.9$ & 0.66 \\
\hline MW/t test known versus new & 0.01 & 0.00 & \\
\hline No-LTD (L7-PKCi) & WT, $n=9$ & $\mathrm{TG}, n=9$ & $M W / t$ test \\
\hline Mouse (s) & $126.4 \pm 11.5$ & $124.3 \pm 6.1$ & 0.87 \\
\hline Empty (s) & $59.4 \pm 7.2$ & $63.9 \pm 6.7$ & 0.66 \\
\hline$M W / t$ test mouse versus empty & $<0.00$ & $<0.00$ & \\
\hline Known mouse (s) & $48.6 \pm 8.3$ & $54.9 \pm 3.1$ & 0.48 \\
\hline New mouse (s) & $123.3 \pm 16.0$ & $104.3 \pm 15.7$ & 0.41 \\
\hline$M W / t$ test known versus new & 0.001 & 0.01 & \\
\hline
\end{tabular}

Mean values \pm SEM of the time spent sniffing the novel mouse or the empty compartment during the sociability test, and the two stimulus mice (known, Stranger 1; new, Stranger 2) during the social recognition phase for the four mouse lines. Statistical differences between genotypes (KO/TG vs WT) and within genotypes (successfulness of the test, i.e. most time spent with mouse compared with empty and new compared with known) were calculated with a Student's $t$ test for normally-distributed data (regular font) or with a Mann-Whitney test for non-normally distributed data (MW; italic font).

Table 2. Olfactory test quantification

\begin{tabular}{lccl}
\hline Less-excit $(\alpha 6$ 6acna1a) & WT, $n=10$ & $\mathrm{~K} 0, n=11$ & MW test \\
\hline Latency to find food (s) & $49.6 \pm 28.1$ & $55.3 \pm 25.4$ & 0.32 \\
No-inhib (L7- $\gamma 2)$ & WT, $n=8$ & K0, $n=9$ & $t$ test \\
\hline Latency to find food (s) & $165.5 \pm 35.1$ & $116.8 \pm 32.1$ & 0.32 \\
No-LTP (L7-PP2B) & WT, $n=10$ & K0, $n=10$ & $M W$ test \\
\hline Latency to find food (s) & $58.2 \pm 30.8$ & $68.4 \pm 33.9$ & 0.93 \\
No-LTD (L7-PKCi) & WT, $n=10$ & TG, $n=13$ & $M W$ test \\
\hline Latency to find food (s) & $148.4 \pm 41.9$ & $131.3 \pm 30.7$ & 0.64 \\
\hline
\end{tabular}

Mean values \pm SEM of the latency to find the buried food for the four mouse lines. Statistical differences wer calculated with a Student's $t$ test for normally-distributed data (regular font) or with a Mann-Whitney test for non-normally distributed data (MW; italic font).

min, each mouse was tested in a second 5 min session to quantify social recognition and preference for a new stranger. A second, unfamiliar mouse was placed in the circular cage that had been empty during the first session. The test mouse had a choice between the first, already-investigated mouse (Stranger 1), and the new unfamiliar mouse (Stranger 2). Again, the time spent sniffing each cage was measured. Animals of both genders were tested. Stimulus mice were of the same gender as the test mouse.

Olfactory test. To rule out a possible bias in our social and fear assessments caused by an impaired olfactory function (Zobel et al., 2010), we subjected the mice to olfactory testing. Each test mouse was placed in a rectangular, transparent box $(40 \times 25 \times 20 \mathrm{~cm})$ with clean bedding sand and allowed to explore the new environment for $15 \mathrm{~min}$ (see Fig. $2 J$ ). 
A

DAYS 1-8: training

platform trial platform trial platform

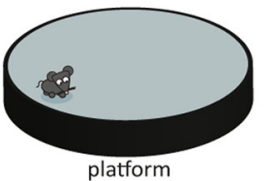

C
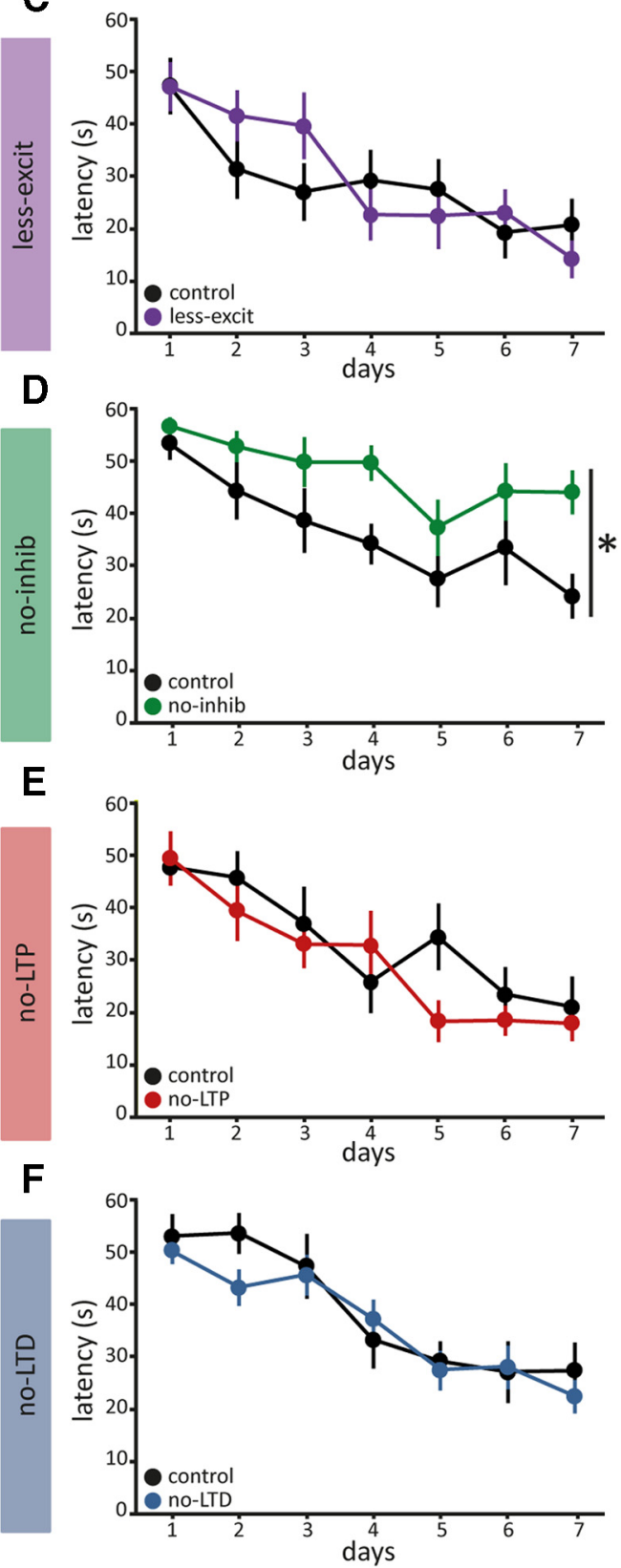

B

DAYS 6,8,22: probe trial
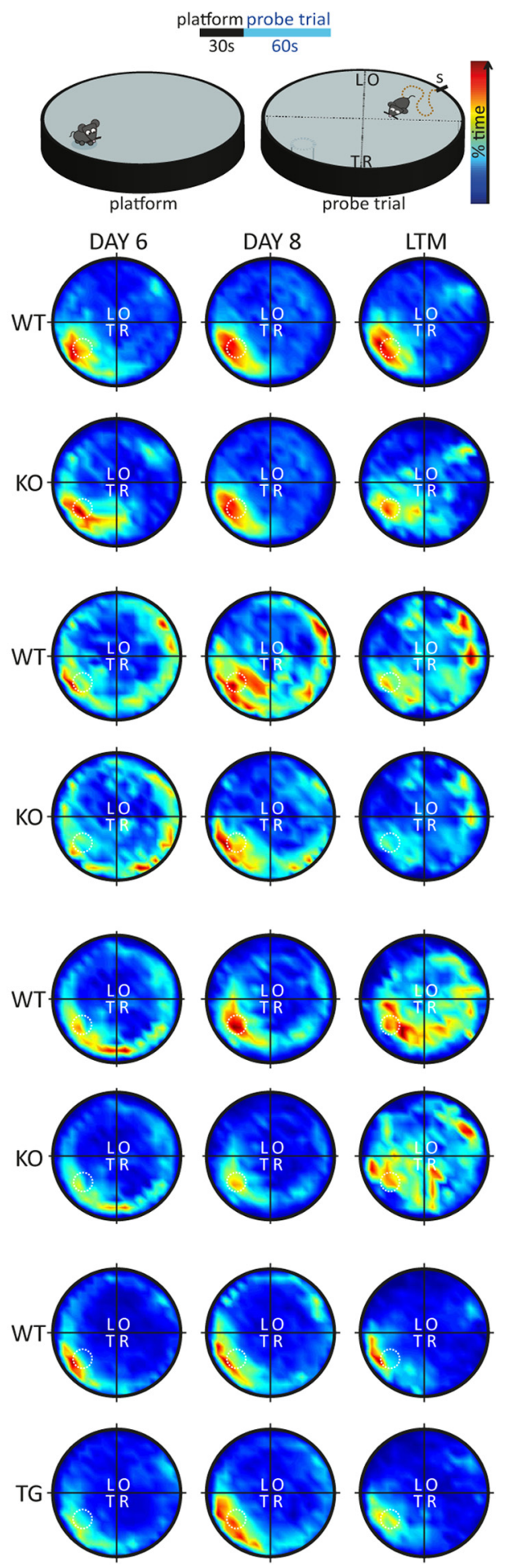

Figure 3. Spatial learning in the Morris watermaze. $\boldsymbol{A}$, Schematic representation of the watermaze training: for 7 consecutive days the mice were placed three times on the submerged platform for $30 \mathrm{~s}$. In between these periods they were released in the pool at semirandom positions and allowed to swim for $60 \mathrm{~s}$, or until they reached the platform. $\boldsymbol{B}$, Schematic representation of the probe trials given at days 6 and 8 , and 2 weeks after the end of the training. The platform was removed, and the mouse swam for $60 \mathrm{~s}$. As a measure of learning we took the amount of time spent by the mouse in the pool quadrant that used to host the platform (target quadrant, T). The other three quadrants are identified in relation to the target quadrant as "opposite" (0), "left" (L), and "right" (R). C, Left, Latency to find the platform during 7 consecutive training days for $\alpha 6$-Cacna1a mice (less-excit, $n=10)$ and their control littermates ( $n=20)$. Right, heat-plot representation of the percentage of time spent in the different quadrants during the $60 \mathrm{~s}$ probe trial in which the platform was removed. Probe trials were administered on days 6 (before the training session) and 8. An additional probe trial to test long-term memory (LTM) was given 2 weeks after day 8. D, Similar to C for L7- $\gamma 2$ mice (no-inhib, $n=12$ ) and their control littermates $(n=12)$. $\boldsymbol{E}$, Similar to C for L7-PP2B mice (no-LTP, $n=10)$ and their control littermates $(n=9)$. $\boldsymbol{F}$, Similar to C for L7-PKCi mice (no-LTD, $n=22)$ and their control littermates $(n=22)$. Values are mean \pm SEM; asterisks indicate significant differences, $p$ values are indicated in the main text and Tables 3-5. 
Afterward, the mouse was gently removed and placed on the experimenter's hand and kept out of sight of the test cage. Meanwhile a piece of peanut-chocolate cookie was buried under the bedding material. The test mouse was then returned to the cage and was given $5 \mathrm{~min}$ to find and dig up the cookie. The latency to start eating the cookie was taken as a measure of olfactory functioning. To avoid that lack of motivation interfered as a confounding factor mice were food-deprived during the night before the experiment.

Morris water maze. To test spatial memory we used the Morris watermaze. This well established paradigm takes advantage of the rodents' natural dislike of swimming and forces them to perform a spatial navigation task finding a hidden platform and leave the water. We used a pool $1.2 \mathrm{~m}$ in diameter, equipped with a platform $11 \mathrm{~cm}$ in diameter submerged $1 \mathrm{~cm}$ below the water surface (see Fig. $3 A$ ). The water was painted milk-white with nontoxic paint and water temperature was kept constant at $26^{\circ} \mathrm{C}$. We used dimmed lighting, and mouse-tracking was performed using SMART version 2.0 (Panlab). Mice were given two trials per day with a $30 \mathrm{~s}$ intertrial interval for 7 consecutive days. During the training sessions, the mouse was first placed on the platform for $30 \mathrm{~s}$. Then it was gently placed in the water at a pseudo-random start position and was given a maximum of $60 \mathrm{~s}$ to find the platform. If the mouse did not find the platform within $60 \mathrm{~s}$, it was placed back on the platform. After $30 \mathrm{~s}$ on the platform, this training procedure was repeated once more. The platform position remained the same during all trials. One hour before the training on days 6 and 8, a probe trial was given to test spatial learning (see Fig. 3B): mice were placed on the platform for $30 \mathrm{~s}$, after which the platform was removed from the pool and the mice were placed in the pool on the side opposite the previous platform position. The mice were then allowed to search for the platform for $60 \mathrm{~s}$. After 2 weeks in which the mice were left in the stable undisturbed (i.e., no cage cleaning, no handling, no subjection to any other experiment), we performed a longterm memory test consisting of a probe trial without the $30 \mathrm{~s}$ spent on the platform before the $60 \mathrm{~s}$ swimming.

Watermaze path analysis. Data obtained from the mouse swimming path on the probe trial on day 8 were analyzed with custom-written Python routines (SciPy, open source scientific tools for Python). For each mouse probe trial, the percentage of time spent in each quadrant was calculated. Subsequently, each swim trajectory was divided in an epoch called "before" (spanning from the start of the probe trial to the moment in which the mouse crossed the platform position) and an epoch named "after" (from the crossing of the platform position to the end of the probe trial). To quantify the strategy used to find the platform, we calculated in the before epoch the latency to reach the platform position (time to platform, i.e., the length in time of the before epoch itself), the total distance swam and deviation from the optimal path (defined as the shortest linear route from the start position to the platform position, see Fig. $7 A$ ). The deviation from optimal was calculated by measuring for each point of the path (sampling frequency $5 \mathrm{~Hz}$ ) the distance to the straight line of the optimal path and summing these distances. In addition, we calculated the time spent in particular pool zones in the before epoch. For this, the pool was divided in three zones (see Fig. $7 B$ ): zone "direct" was defined as a rectangle parallel to the shortest route from the starting position to the platform; zone "circling" was formed by two concentric circles where each circle crosses the edge of the platform; and zone "thigmotaxis" consisted of a circular zone delimited by the outer border of the platform location and the pool border. Finally, we quantified the degree of certainty of reaching platform position during the after epoch, as in after having reached the appropriate position without actually finding the platform, which was not there anymore. Hereto, we divided the pool in two different zones (see Fig. 7C), namely the "target" zone, which is a circle on the center of the platform, and the "opposite" zone, which is a circle on the center of the position where the mouse was released (exactly opposite to the target zone). The time spent in each zone was calculated for each mouse during this part of the after epoch.

\section{Fear conditioning}

Fear-conditioning training was performed in a testing chamber $(26 \times$ $22 \times 18 \mathrm{~cm}$; San Diego Instruments) made of Plexiglas and equipped with a CCD camera to monitor activity and a grid floor via which the
Table 3. Watermaze: probe trial day 6 quantification

\begin{tabular}{|c|c|c|c|}
\hline Less-excit ( $\alpha 6$ Cacna1a) & WT, $n=20$ & $\mathrm{~K} 0, n=10$ & $M W / t$ test \\
\hline Resting (time, \%) & $3.4 \pm 0.7$ & $4.9 \pm 1.0$ & 0.09 \\
\hline \multirow[t]{2}{*}{ Speed $(\mathrm{cm} / \mathrm{s})$} & $14.0 \pm 0.3$ & $13.7 \pm 0.4$ & 0.56 \\
\hline & & & Pearson $\chi^{2}$ \\
\hline Target quadrant (time, \%) & $44.9 \pm 2.4$ & $44.5 \pm 3.1$ & 0.63 \\
\hline Right quadrant (time, $\%)$ & $19.1 \pm 1.2$ & $20.7 \pm 2.1$ & 0.36 \\
\hline Opposite quadrant (time, \%) & $16.6 \pm 1.7$ & $17.5 \pm 3.0$ & 0.44 \\
\hline Left quadrant (time, \%) & $19.5 \pm 1.8$ & $17.3 \pm 1.6$ & 0.26 \\
\hline ANOVA time in different quadrants & 0.00 & 0.00 & \\
\hline No-inhib $(L 7-\gamma 2)$ & WT, $n=12$ & $\mathrm{~K} 0, n=12$ & $M W / t$ test \\
\hline Resting (time, \%) & $4.5 \pm 2.2$ & $15.0 \pm 4.4$ & 0.01 \\
\hline \multirow[t]{2}{*}{ Speed $(\mathrm{cm} / \mathrm{s})$} & $13.9 \pm 0.6$ & $11.4 \pm 0.9$ & 0.03 \\
\hline & & & Pearson $\chi^{2}$ \\
\hline Target quadrant (time, \%) & $29.6 \pm 4.1$ & $28.1 \pm 4.1$ & 0.46 \\
\hline Right quadrant (time, \%) & $25.5 \pm 3.9$ & $31.5 \pm 2.9$ & 0.40 \\
\hline Opposite quadrant (time, \%) & $24.7 \pm 3.2$ & $21.6 \pm 2.3$ & 0.52 \\
\hline Left quadrant (time, \%) & $20.2 \pm 2.8$ & $19.0 \pm 2.2$ & 0.46 \\
\hline ANOVA time in different quadrants & 0.33 & 0.02 & \\
\hline No-LTP (L7-PP2B) & WT, $n=9$ & $\mathrm{~K} 0, n=10$ & $M W / t$ test \\
\hline Resting (time, \%) & $3.5 \pm 1.6$ & $20.2 \pm 4.6$ & 0.00 \\
\hline \multirow[t]{2}{*}{ Speed $(\mathrm{cm} / \mathrm{s})$} & $14.7 \pm 0.5$ & $11.3 \pm 0.7$ & 0.00 \\
\hline & & & Pearson $\chi^{2}$ \\
\hline Target quadrant (time, \%) & $36.9 \pm 3.5$ & $49.0 \pm 5.3$ & 0.40 \\
\hline Right quadrant (time, \%) & $26.8 \pm 2.5$ & $18.3 \pm 2.3$ & 0.44 \\
\hline Opposite quadrant (time, \%) & $19.1 \pm 2.4$ & $14.2 \pm 3.0$ & 0.43 \\
\hline Left quadrant (time, \%) & $17.2 \pm 2.9$ & $18.5 \pm 3.0$ & 0.33 \\
\hline ANOVA time in different quadrants & 0.00 & 0.00 & \\
\hline No-LTD (L7-PKCi) & WT, $n=22$ & $\mathrm{TG}, n=22$ & $M W / t$ test \\
\hline Resting (time, \%) & $12.2 \pm 3.5$ & $8.5 \pm 2.3$ & 0.45 \\
\hline \multirow[t]{2}{*}{ Speed $(\mathrm{cm} / \mathrm{s})$} & $12.5 \pm 0.6$ & $12.2 \pm 0.6$ & 0.33 \\
\hline & & & Pearson $\chi^{2}$ \\
\hline Target quadrant (time, \%) & $42.3 \pm 3.8$ & $41.0 \pm 3.4$ & 0.47 \\
\hline Right quadrant (time, \%) & $21.6 \pm 2.2$ & $25.1 \pm 3.1$ & 0.45 \\
\hline Opposite quadrant (time, \%) & $16.4 \pm 1.8$ & $18.4 \pm 1.8$ & 0.62 \\
\hline Left quadrant (time, \%) & $19.8 \pm 2.2$ & $15.5 \pm 2.1$ & 0.42 \\
\hline ANOVA time in different quadrants & 0.00 & 0.00 & \\
\hline
\end{tabular}

Mean values \pm SEM of the percentage of time spent resting, the average swimming speed and the percentage of time spent in the four different quadrants (target, right, left, and opposite) during the $60 \mathrm{~s}$ probe trial given at day 6 (before the training session) for the four mouse lines. Statistical differences between genotypes (K0/TG vs WT) were calculated with a Student's $t$ test for normally-distributed data (regular font) or with a Mann-Whitney test for non-normally distributed data (MW; italic font), and with a Pearson $\chi 2$ for the time spent in different zones. Successfulness of the test (i.e., most of time spent in quadrant target) was calculated per genotype with an ANOVA test.

foot-shock could be administered (see Fig. 4A). The testing chamber was placed inside a sound proof isolation cubicle. Before the training session, the ability of the mice to hear was assessed by shortly exposing them to a high-pitched sound (i.e., metal stick hitting empty glass bottle) and monitoring their body startle. Only one mouse ( $\alpha 6$ Cacnala WT) failed to show startles and was therefore excluded from the cued experiments. Training and context fear testing occurred in the presence of the metal grid floor, square walls, white light, and ethanol smell (Cage A). For the cued fear testing the chamber was modified by inserting a plastic foil to cover the metal grid plus two oblique walls, to create a triangular environment; the testing was performed in the dark and in the presence of acetic acid smell (Cage B). Fear response was automatically quantified by the software by measuring the duration of freezing behavior, which was defined as a total lack of movement apart from respiration.

Experiment 1: classic protocol. Training consisted of placing the mouse in Cage A and, $120 \mathrm{~s}$ later, presenting it with a tone $(5 \mathrm{KHz}, 20 \mathrm{~s}, 85 \mathrm{~dB})$ that coterminated with a shock $(2 \mathrm{~s}, 0.4 \mathrm{~mA}$; see Fig. $4 A)$. The mouse remained in the chamber for $30 \mathrm{~s}$ after shock delivery. Freezing behavior 
Table 4. Watermaze: probe trial day 8 quantification

\begin{tabular}{|c|c|c|c|}
\hline Less-excit ( $\alpha 6$ Cacna1a) & WT, $n=20$ & $\mathrm{~K} 0, n=10$ & $M W / t$ test \\
\hline \multirow[t]{2}{*}{ Speed $(\mathrm{cm} / \mathrm{s})$} & $\begin{array}{r}2.6 \pm 0.4 \\
14.2 \pm 0.2\end{array}$ & $\begin{array}{r}2.4 \pm 0.7 \\
14.1 \pm 0.5\end{array}$ & $\begin{array}{l}0.51 \\
0.85\end{array}$ \\
\hline & & & Pearson $\chi^{2}$ \\
\hline Target quadrant (time, \%) & $46.1 \pm 3.5$ & $45.3 \pm 5.8$ & 0.36 \\
\hline Right quadrant (time, \%) & $18.1 \pm 1.5$ & $15.8 \pm 2.1$ & 0.44 \\
\hline Opposite quadrant (time, \%) & $17.8 \pm 1.9$ & $15.3 \pm 1.4$ & 0.37 \\
\hline Left quadrant (time, \%) & $18.0 \pm 1.9$ & $18.6 \pm 1.2$ & 0.26 \\
\hline ANOVA time in different quadrants & 0.00 & 0.00 & \\
\hline No-inhib $(L 7-\gamma 2)$ & WT, $n=12$ & $\mathrm{~K} 0, n=12$ & $M W / t$ test \\
\hline Resting (time, \%) & $7.3 \pm 2.7$ & $12.7 \pm 3.1$ & 0.11 \\
\hline \multirow[t]{2}{*}{ Speed $(\mathrm{cm} / \mathrm{s})$} & $13.4 \pm 0.7$ & $11.4 \pm 0.8$ & 0.09 \\
\hline & & & Pearson $\chi^{2}$ \\
\hline Target quadrant (time, \%) & $37.7 \pm 3.9$ & $38.9 \pm 4.7$ & 0.29 \\
\hline Right quadrant (time, \%) & $26.2 \pm 3.0$ & $26.7 \pm 3.7$ & 0.44 \\
\hline Opposite quadrant (time, \%) & $19.6 \pm 3.1$ & $20.6 \pm 3.0$ & 0.44 \\
\hline Left quadrant (time, \%) & $16.5 \pm 1.6$ & $13.6 \pm 1.4$ & 0.40 \\
\hline ANOVA time in different quadrants & 0.00 & 0.00 & \\
\hline No-LTP (L7-PP2B) & $\mathrm{WT}, n=10$ & $\mathrm{~K} 0, n=10$ & $M W / t$ test \\
\hline Resting (time, \%) & $1.6 \pm 0.8$ & $20.4 \pm 4.6$ & 0.00 \\
\hline \multirow[t]{2}{*}{ Speed $(\mathrm{cm} / \mathrm{s})$} & $14.5 \pm 0.6$ & $10.6 \pm 0.6$ & 0.00 \\
\hline & & & Pearson $\chi^{2}$ \\
\hline Target quadrant (time, \%) & $41.6 \pm 4.4$ & $45.0 \pm 6.4$ & 0.40 \\
\hline Right quadrant (time, \%) & $21.3 \pm 3.3$ & $22.3 \pm 3.8$ & 0.44 \\
\hline Opposite quadrant (time, \%) & $16.8 \pm 2.2$ & $16.5 \pm 2.7$ & 0.43 \\
\hline Left quadrant (time, \%) & $20.3 \pm 2.8$ & $16.3 \pm 3.0$ & 0.33 \\
\hline ANOVA time in different quadrants & 0.00 & 0.00 & \\
\hline No-LTD (L7-PKCi) & WT, $n=22$ & $\mathrm{TG}, n=22$ & $M W / t$ test \\
\hline Resting (time, \%) & $11.8 \pm 2.8$ & $6.2 \pm 1.5$ & 0.12 \\
\hline \multirow[t]{2}{*}{ Speed $(\mathrm{cm} / \mathrm{s})$} & $12.8 \pm 0.5$ & $13.9 \pm 0.6$ & 0.15 \\
\hline & & & Pearson $\chi^{2}$ \\
\hline Target quadrant (time, \%) & $39.7 \pm 3.2$ & $44.6 \pm 3.8$ & 0.34 \\
\hline Right quadrant (time, \%) & $22.1 \pm 2.2$ & $22.1 \pm 2.4$ & 0.64 \\
\hline Opposite quadrant (time, \%) & $19.9 \pm 2.2$ & $17.8 \pm 2.0$ & 0.18 \\
\hline Left quadrant (time, \%) & $18.3 \pm 2.2$ & $15.5 \pm 1.7$ & 0.24 \\
\hline ANOVA time in different quadrants & 0.00 & 0.00 & \\
\hline
\end{tabular}

Mean values \pm SEM of the percentage of time spent resting, the average swimming speed and the percentage of time spent in the four different quadrants (target, right, left, and opposite) during the $60 \mathrm{~s}$ probe trial given at day 8 for the four mouse lines. Statistical differences between genotypes (K0/TG vs WT) were calculated with a Student's $t$ test for normally-distributed data (regular font) or with a Mann-Whitney test for non-normally distributed data (MW; italic font), and with a Pearson $\chi^{2}$ for the time spent in different zones. Successfulness of the test (i.e., most of time spent in quadrant target) was calculated per genotype with an ANOVA test.

was assessed during the first $120 \mathrm{~s}$ (context baseline). Contextual fear testing occurred $24 \mathrm{~h}$ after training. Mice were placed in the same Cage B for $180 \mathrm{~s}$ and the freezing behavior was assessed (context test). Cued fear testing occurred $48 \mathrm{~h}$ after training. Mice were placed in Cage B for $120 \mathrm{~s}$ and left unperturbed, and then for the subsequent $180 \mathrm{~s}$ the same tone was presented as that during the training session. Freezing behavior was measured for both the first period (cued baseline) and the second one (cued test).

Experiment 2: Torino protocol. We subjected a second group of mice, which did not undergo the classic fear conditioning testing, to the cued fear conditioning procedure developed by the group of P. Strata at the University of Torino (Sacchetti et al., 2004; see Fig. 6A). Once placed inside Cage A, the mice were left undisturbed for $120 \mathrm{~s}$. After this time, a tone $(3.5 \mathrm{KHz}, 70 \mathrm{~dB}, 6 \mathrm{~s})$ was administered eight times at $30 \mathrm{~s}$ intervals. The last second of each tone was paired with an electric foot shock $(0.75$ $\mathrm{mA}$ ). After $24 \mathrm{~h}$, the animals were placed in Cage B, where they received a series of eight acoustic stimuli identical to those used during the training session.

Extinction of cue fear conditioning. To assess the animals' ability to extinguish the fear memory, after the cued training in Cage A (either
Table 5. Watermaze: probe trial long-term memory (LTM) quantification

\begin{tabular}{|c|c|c|c|}
\hline Less-excit ( $\alpha 6$ Cacna1a) & $\mathrm{WT}, n=20$ & $\mathrm{~K} 0, n=10$ & $M W / t$ test \\
\hline \multirow[t]{2}{*}{ Speed $(\mathrm{cm} / \mathrm{s})$} & $\begin{array}{r}6.2 \pm 1.7 \\
12.4 \pm 0.4\end{array}$ & $\begin{array}{r}8.2 \pm 3.0 \\
11.9 \pm 0.6\end{array}$ & $\begin{array}{l}0.72 \\
0.53\end{array}$ \\
\hline & & & Pearson $\chi^{2}$ \\
\hline Target quadrant (time, \%) & $47.6 \pm 3.2$ & $43.9 \pm 5.8$ & 0.47 \\
\hline Right quadrant (time, $\%$ ) & $14.8 \pm 1.8$ & $17.7 \pm 3.2$ & 0.48 \\
\hline Opposite quadrant (time, \%) & $18.6 \pm 1.8$ & $18.8 \pm 3.6$ & 0.67 \\
\hline Left quadrant (time, \%) & $19.1 \pm 2.4$ & $19.7 \pm 3.1$ & 0.31 \\
\hline ANOVA time in different quadrants & 0.00 & 0.00 & \\
\hline No-inhib (L7- $\gamma 2)$ & WT, $n=10$ & $\mathrm{~K} 0, n=11$ & $M W / t$ test \\
\hline Resting (time, \%) & $10.3 \pm 3.9$ & $30.8 \pm 7.9$ & 0.07 \\
\hline \multirow[t]{2}{*}{ Speed $(\mathrm{cm} / \mathrm{s})$} & $11.4 \pm 0.6$ & $8.7 \pm 1.0$ & 0.03 \\
\hline & & & Pearson $\chi^{2}$ \\
\hline Target quadrant (time, \%) & $29.7 \pm 4.9$ & $28.5 \pm 5.4$ & 0.40 \\
\hline Right quadrant (time, \%) & $26.8 \pm 3.7$ & $27.8 \pm 5.3$ & 0.52 \\
\hline Opposite quadrant (time, \%) & $27.6 \pm 4.5$ & $24.1 \pm 4.0$ & 0.33 \\
\hline Left quadrant (time, \%) & $15.9 \pm 3.3$ & $19.7 \pm 3.3$ & 0.40 \\
\hline ANOVA time in different quadrants & 0.10 & 0.52 & \\
\hline No-LTP (L7-PP2B) & WT, $n=10$ & $\mathrm{~K} 0, n=10$ & $M W / t$ test \\
\hline Resting (time, \%) & $3.2 \pm 0.7$ & $15.7 \pm 4.6$ & 0.01 \\
\hline \multirow[t]{2}{*}{ Speed $(\mathrm{cm} / \mathrm{s})$} & $13.9 \pm 0.5$ & $11.1 \pm 0.6$ & 0.001 \\
\hline & & & Pearson $\chi^{2}$ \\
\hline Target quadrant (time, \%) & $32.9 \pm 3.7$ & $32.5 \pm 3.3$ & 0.40 \\
\hline Right quadrant (time, \%) & $28.2 \pm 3.2$ & $23.7 \pm 3.4$ & 0.38 \\
\hline Opposite quadrant (time, \%) & $21.6 \pm 3.3$ & $22.7 \pm 3.4$ & 0.45 \\
\hline Left quadrant (time, \%) & $17.4 \pm 3.1$ & $21.2 \pm 3.5$ & 0.40 \\
\hline ANOVA time in different quadrants & 0.01 & 0.10 & \\
\hline No-LTD (L7-PKCi) & WT, $n=22$ & $\mathrm{TG}, n=22$ & $M W / t$ test \\
\hline Resting (time, \%) & $23.8 \pm 3.9$ & $19.1 \pm 3.6$ & 0.29 \\
\hline \multirow[t]{2}{*}{ Speed $(\mathrm{cm} / \mathrm{s})$} & $9.9 \pm 0.6$ & $10.0 \pm 0.6$ & 0.91 \\
\hline & & & Pearson $\chi^{2}$ \\
\hline Target quadrant (time, \%) & $47.6 \pm 4.4$ & $46.9 \pm 4.5$ & 0.43 \\
\hline Right quadrant (time, \%) & $17.7 \pm 2.5$ & $19.8 \pm 3.0$ & 0.37 \\
\hline Opposite quadrant (time, \%) & $18.8 \pm 3.1$ & $18.9 \pm 3.8$ & 0.33 \\
\hline Left quadrant (time, \%) & $16.6 \pm 2.6$ & $14.5 \pm 2.7$ & 0.55 \\
\hline ANOVA time in different quadrants & 0.00 & 0.00 & 0.00 \\
\hline
\end{tabular}

Mean values \pm SEM of the percentage of time spent resting, the average swimming speed and the percentage of time spent in the four different quadrants (target, right, left, and opposite) during the 60 s probe trial given 2 weeks after the previous probe trial for the four mouse lines. Statistical differences between genotypes (KO/TG vs WT) were calculated with a Student's $t$ test for normally-distributed data (regular font) or with a Mann-Whitney test for non-normally distributed data (MW; italic font), and with a Pearson $\chi^{2}$ for the time spent in different zones. Successfulness of the test (i.e., most of time spent in quadrant target) was calculated per genotype with an ANOVA test.

classic or Torino protocol) we repeated for 10 consecutive days the cued test paradigm in Cage $\mathrm{B}$, and we quantified the decreasing amount of freezing during tone exposure as a measure of working memory.

\section{Open field}

To further test tendencies of anxiety and locomotion behavior, unhandled individual mice were placed in a circular, brightly-lit open field (120 cm diameter), and the total distance traveled, together with the average speed of each mouse was recorded for $10 \mathrm{~min}$ (see Fig. 9A; SMART software, Panlab). Additionally, during the analysis the arena was divided into three concentric zones called outer (peripherical, donut-shaped, minor radius $15 \mathrm{~cm}$ ), middle (intermediate, donutshaped, minor radius $15 \mathrm{~cm}$ ) and inner (central, circular, radius $25 \mathrm{~cm}$; see Fig. $9 B$ ). The percentage of time spent by each mouse in the three zones was automatically calculated by the software and taken as a measure of general anxiety.

\section{Accelerating rotarod}

Finally, to rule out potential caveats due to more hidden deficits in motor performance that might not be revealed in the open field test, we tested 
A

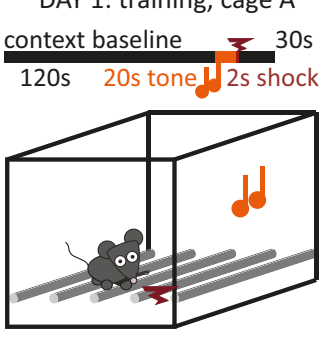

DAY 2: context test, cage A
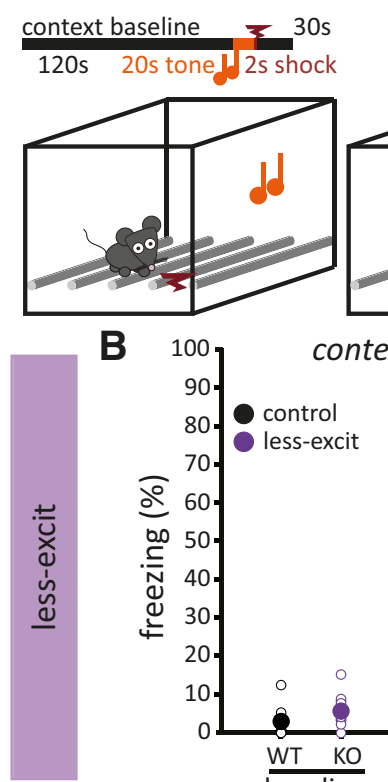

B
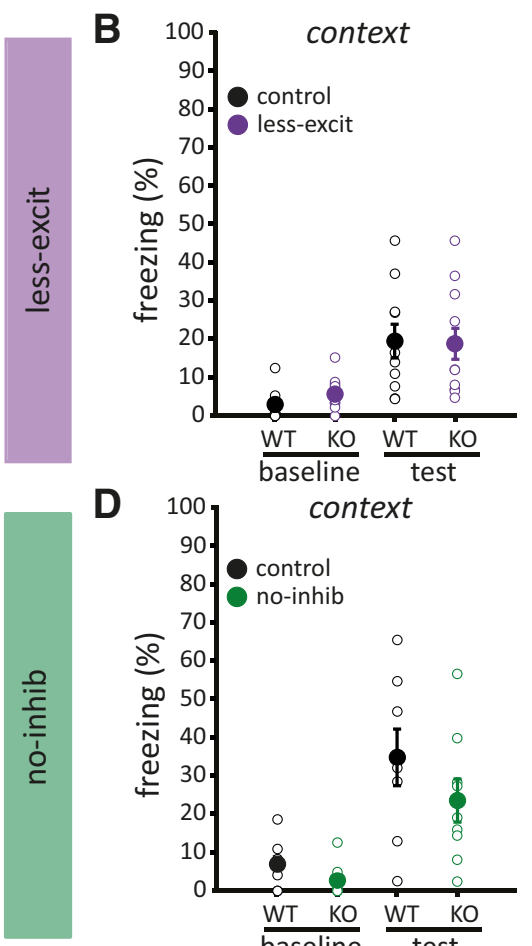

D
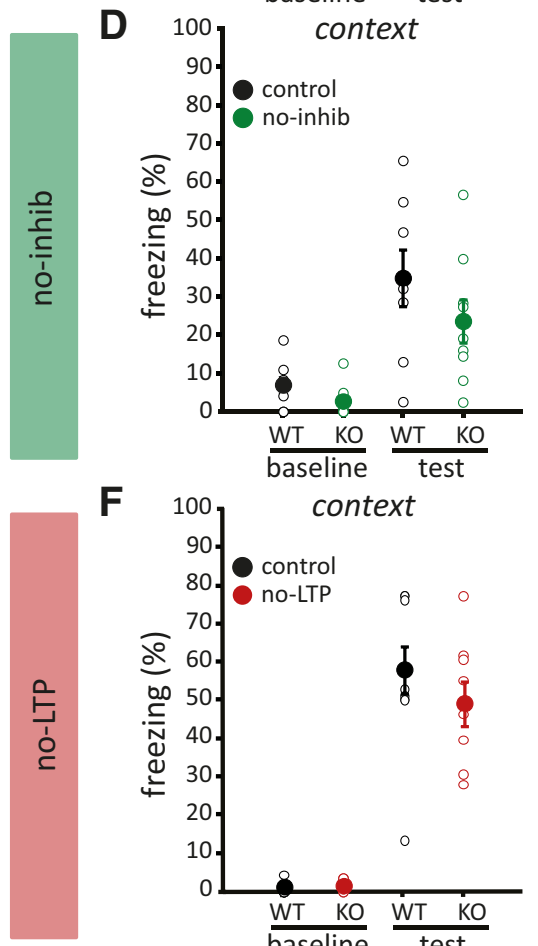

$\mathbf{F}$
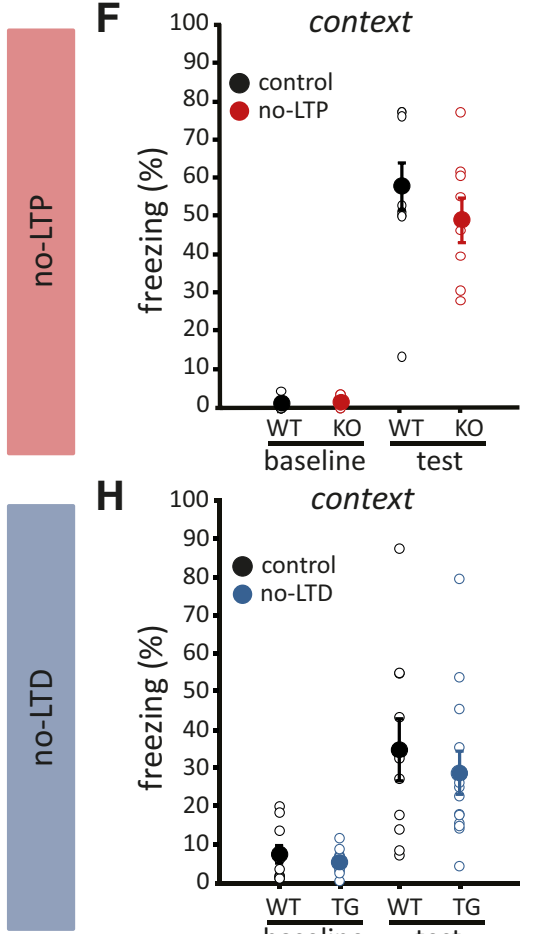

H

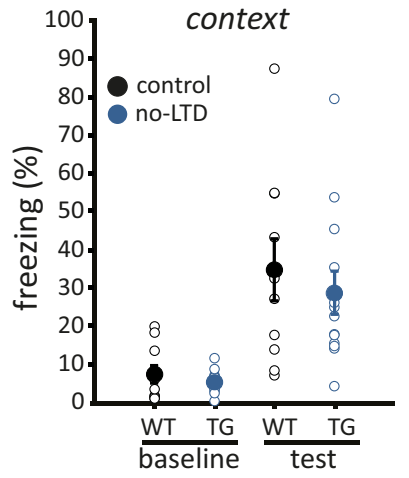

DAY 3: cue test, cage B

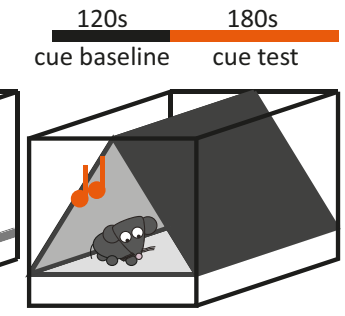

C

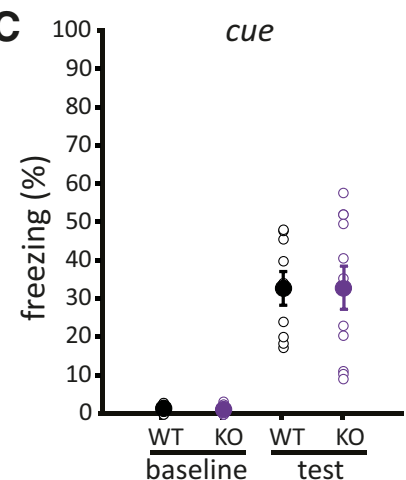

E

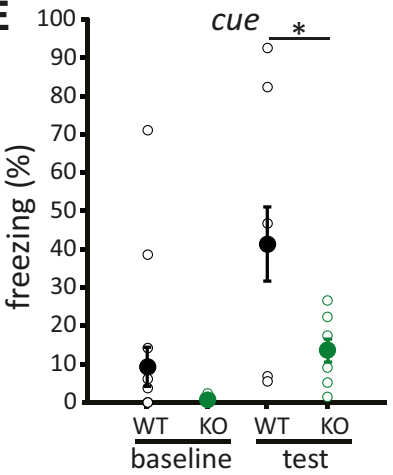

G
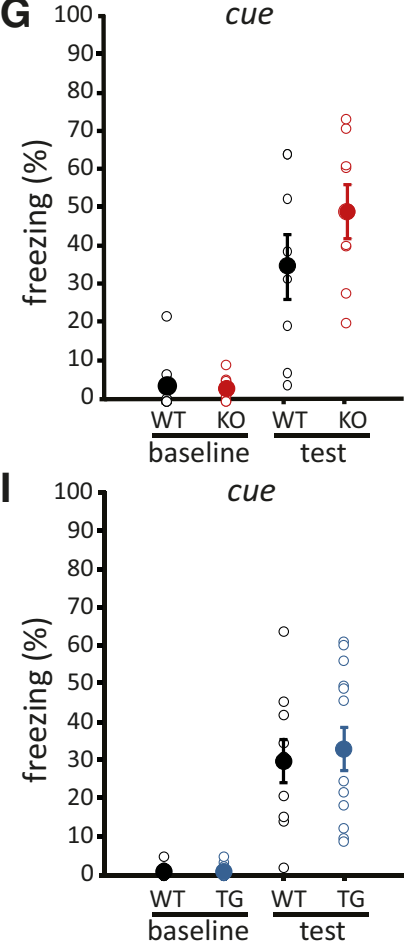

Figure 4. Classic contextual and cued fear conditioning. $\boldsymbol{A}$, Graphical representation of the classic fear conditioning task. On day 1 mice were placed in a bright square chamber, with gridded floor and ethanol smell (Cage A), and left free to explore it for $120 \mathrm{~s}$

motor coordination using the accelerating rotarod (see Fig. 10A; 4-40 rpm in 5 min; model 7650, Ugo Basile Biological Research Apparatus). Mice were given two trials per day with a 45-60 min intertrial interval for 5 consecutive days. For each day we calculated the average time spent on the rotarod, or of the time until the mouse had made three consecutive rotations on the rotarod. The maximum duration of each trial was $5 \mathrm{~min}$.

\section{Data analyses}

All values are shown as mean \pm SEM. All $p$ values were determined for mutants against their littermate controls using a two-tailed Student's $t$ test or an ANOVA for repeated measures if not stated otherwise. If data were not normally distributed, a nonparametric MannWhitney (MW) $U$ test was used instead of a $t$ test. To avoid biasing our conclusions (which were mostly negative) toward a lack of statistical significance, the $p$ values reported were calculated without corrections for multiple testing.

\section{Results}

We used a wide battery of well established tests encompassing cognitive and emotional behaviors in $\alpha 6$-Cacnala (lessexcit), L7- $\gamma 2$ (no-inhib), L7-PP2B (noLTP), and L7-PKCi mice (no-LTD; Fig. 1; De Zeeuw et al., 1998; Wulff et al., 2009; Schonewille et al., 2010; Galliano et al., 2013). We probed social behavior with a sociability and social recognition test, spatial learning (short- and long-term) with the classic watermaze paradigm, emotional learning and anxiety testing with context-dependent and cue-dependent fear conditioning, as well as the open-field test, and frontal functions (i.e., decision making and working memory) by analyzing the strategies used to find the escape platform in the watermaze test and

$\leftarrow$

(context baseline). A 20 s tone was then played, and the last $2 \mathrm{~s}$ of it were paired with a foot shock; after 30 additional seconds the mice were put back in the home cage. On day 2 they returned to Cage A for $180 \mathrm{~s}$ (context test). On day 3 they were placed in a dark pyramidal chamber, with smooth floor and acetic acid smell (Cage B), left free to explore it for 120 s (cue baseline), and then exposed to a 180 s tone (cue test). The time spent by the mice freezing was taken as a measure of fear. $\boldsymbol{B}$, Time spent freezing by $\alpha 6$-Cacna1a mice (less-excit, $n=11$ ) and their control littermates $(n=10)$ during the context baseline period (day 1 ) and the context test (day 2) in cage A. C, Time spent freezing by the same $\alpha 6$-Cacna1a mice (KO and (trl) in Cage B on day 3 during cue baseline and test. $\boldsymbol{D}, \boldsymbol{E}$, Similar to $\boldsymbol{B}, \boldsymbol{C}$ for L7- $\gamma 2$ mice (no-inhib, $n=9$ ) and their control littermates $(n=8) . \boldsymbol{F}, \mathbf{G}$, Similar to $\boldsymbol{B}, \boldsymbol{C}$ for L7-PP2B mice (no-LTP, $n=8)$ and their control littermates $(n=8)$. $\boldsymbol{H}$, I, Similar to $\boldsymbol{B}$, C for L7-PKCi mice (no-LTD, $n=13$ ) and their control littermates $(n=10)$. Open circles represent individual data points; filled circles are mean \pm SEM; asterisks indicate significant differences, $p$ values are indicated in the main text and Table 6. 
by extinguishing the cue-dependent fear conditioning.

\section{Cerebellar mutants did not show a phenotype in social behavior}

Given the evidence of a plausible cerebellar contribution to the autism-spectrum symptoms described in humans (Courchesne, 1997; Critchley et al., 2000; Garrard et al., 2008), we tested the social behavior of our mice. During the first phase of the experiment (called sociability; Fig. 2A; see Materials and Methods), all mice spent more time exploring the circular cage containing a novel mouse (Stranger 1) than the opposite, empty one (all $p<$ 0.01 ); this effect did not differ between the genotypes in any of the lines (all $p>0.18$; Fig. 2; Table 1). Also during the social recognition phase, during which a second novel mouse (Stranger 2) was placed in the previously empty compartment, we did not find any difference between genotypes (all $p>0.08$ ), and all mice showed a strong preference for the Stranger 2 mouse (all $p<0.02$; Fig. 2; Table 1). In addition, the basic olfactory test did not show any indication for aberrant olfactory function in that the latency to start eating the buried food was similar between genotypes (all $p>0.32$; Fig. 2; Table 2). Thus, we conclude that the examined genetic manipulations impairing GC and PC function were insufficient to significantly modify the behavior of the mice when subjected to a standard sociability and social recognition test.

\section{Cerebellar mutants show limited abnormalities in spatial learning}

Recent evidence implied that the cerebellum is involved in shaping specific aspects of spatial learning (Burguière et al., 2005, 2010; Rochefort et al., 2011). We tested the general spatial navigation capabilities of our mutants by subjecting them to the standard hippocampal-dependent spatial learning task, i.e., the Morris watermaze. In this test the animals are trained over 7 consecutive days to locate a submerged platform in a circular pool filled with opaque water using distal visual cues (Fig. 3A). All groups, except the no-inhib mice, showed a significant reduction of the time required to find the platform across training days that was similar to that of controls (repeated-measures ANOVA $p$ values for control vs mutant comparison: less-excit $=0.97$, no-inhib $=0.00$, no-LTP $=0.27$, no-LTD $=0.87$; Fig. 3). The phenotype observed in the no-inhib mice can be at least partially explained by the clear trend of an increased resting time and lower swim speed ( $p$ values at day 6 were resting time $p=0.01$ and swim speed $p=0.03$; Table 3 ). This suboptimal swimming behavior, which could be due to either a mild motor impairment or lack of motivation, was observed also in the no-LTP mice ( $p$ values at day 6 were resting time $p=0.00$ and swim speed $p=0.00)$, but in this case they did not affect the latency curve (Fig. 3E).

After 5 and 7 days of training we examined whether the mutants had indeed learned the location of the platform by subjecting them to a probe trial in which the platform was removed and quantifying the time spent in the proximity of the previous platform position (probe trials days 6 and 8; Fig. 3; Tables 3,4). Although at day 6 some groups of both mutants and control littermates still showed poor learning, all probe trials given at day 8 indicated that mice spent significantly more time in the quadrant where the platform had been situated, and thus succeeded in acquiring a spatial memory (Tables 3,4 for a comprehensive statistical characterization). The retention of this memory was tested by giving a third probe trial 2 weeks later (with no training or any other testing in the meantime). Again, although the degree of retained memory was variable between lines (WT mice in-
Table 6. Fear conditioning quantification, classic protocol

\begin{tabular}{lccc}
\hline Less-excit ( $\alpha 6$ Cacna1a) & WT, $n=10$ & $\mathrm{~K} 0, n=11$ & MW/t test \\
\hline Context baseline (\%) & $3.0 \pm 1.2$ & $5.7 \pm 1.3$ & 0.09 \\
Context test (\%) & $19.6 \pm 4.5$ & $18.9 \pm 4.2$ & 0.91 \\
MW/t test context & 0.00 & 0.00 & \\
Cue baseline (\%) & $1.6 \pm 0.4$ & $1.3 \pm 0.4$ & 0.57 \\
Cue test (\%) & $33.1 \pm 4.4$ & $33.1 \pm 5.7$ & 0.99 \\
MW/t test cue & 0.00 & 0.00 & \\
No-inhib (L7- $\gamma 2)$ & WT, $n=8$ & $\mathrm{~K} 0, n=9$ & MW/t test \\
\hline Context baseline (\%) & $7.0 \pm 2.2$ & $2.8 \pm 1.3$ & 0.14 \\
Context test (\%) & $35.0 \pm 7.4$ & $23.7 \pm 5.6$ & 0.24 \\
MW/t test context & 0.00 & 0.00 & \\
Cue baseline (\%) & $9.3 \pm 5.0$ & $0.8 \pm 0.3$ & 0.27 \\
Cue test (\%) & $41.5 \pm 9.1$ & $13.7 \pm 3.0$ & 0.02 \\
MW/t test cue & 0.01 & 0.00 & \\
No-LTP (L7-PP2B) & WT, $n=8$ & $\mathrm{~K} 0, n=8$ & MW/t test \\
\hline Context baseline (\%) & $1.3 \pm 0.5$ & $1.4 \pm 0.7$ & 0.15 \\
Context test (\%) & $28.6 \pm 14.8$ & $29.0 \pm 16.5$ & 0.30 \\
MW/t test context & 0.00 & $<0.00$ & \\
Cue baseline (\%) & $4.2 \pm 2.7$ & $3.3 \pm 1.2$ & 0.52 \\
Cue test (\%) & $35.5 \pm 8.5$ & $49.8 \pm 7.1$ & 0.22 \\
MW/t test cue & 0.00 & 0.00 & \\
No-LTD (L7-PKCi) & WT, $n=10$ & $\mathrm{TG}, n=13$ & MW/t test \\
\hline Context baseline (\%) & $7.6 \pm 2.3$ & $5.5 \pm 0.81$ & 0.95 \\
Context test (\%) & $34.9 \pm 8.1$ & $28.9 \pm 5.7$ & 0.62 \\
MW/t test context & 0.00 & 0.00 & \\
Cue baseline (\%) & $1.1 \pm 0.5$ & $1.1 \pm 0.5$ & 0.72 \\
Cue test (\%) & $30.0 \pm 5.7$ & $33.2 \pm 5.8$ & 0.80 \\
MW/t test cue & 0.00 & 0.00 & \\
\hline & & & \\
\hline
\end{tabular}

Mean values \pm SEM of the percentage of time spent freezing during contextual testing (day 1 baseline, day 2 test) and cued testing (day 3 baseline and test; Fig. 4A; see Materials and Methods for protocol details) for the four mouse lines. Statistical differences between genotypes (KO/TG vs WT) and within genotypes (successfulness of the test, i.e., most time spent freezing during test compared to baseline periods) were calculated with a Student's $t$ test for normally distributed data (regular font) or with a Mann-Whitney test for non-normally distributed data (MW; italic font).

cluded), no difference was observed between genotypes with respect to the time spent in the target quadrant (Fig. 3; Table 5). Together, these data indicate that none of the cerebellar mutations tested, resulted in significant differences in spatial learning and spatial memory.

\section{Cerebellar mutants show no consistent impairment of fear learning}

Prompted by the increasing body of evidence regarding a potential cerebellar involvement in emotional processing (Schmahmann and Sherman, 1997; Timmann et al., 2010; Schraa-Tam et al., 2012) and some forms of Pavlovian conditioning (Ivarsson et al., 2000; Boele et al., 2010), we assessed two widely used types of associative emotional memory formation: contextual and cued fear conditioning. During these tests, mice acquired fear responses to either the context in which they received an aversive unconditioned stimulus (an electric foot shock) or a previously neutral conditioned stimulus (CS; a tone serving as cue) that was paired with the aversive stimulus.

Animals were placed in a context in which they received a shock while hearing the conditioning tone, and $24 \mathrm{~h}$ after this training session they were placed in the same context during which we measured their freezing behavior in the absence of a conditioning tone. Forty-eight hours after training, mice were placed in a new environment and allowed to freely explore for 2 min before being presented with the conditioning tone. Freezing behavior was assessed both during the baseline and cue test peri- 
ods (Fig. 4A; see Materials and Methods). Analogous to the watermaze results, no differences between genotypes were found in the contextual learning (all $p>$ 0.24; Fig. 4; Table 6). For the cued learning, only the no-inhib mice showed a significant difference (no-inhib $p=0.02$; Fig. 4E; Table 6).

To confirm the phenotype of no-inhib mice, we repeated the experiment with a new group of L7- $\gamma 2$ mice. Furthermore, to avoid any potential confounds regarding the specificity for the cue memory, we tested the response to the tone stimulus first (at day 2) and the response to context last (at day 3; Fig. 5A). With this second group of mice we found no difference in the amount of freezing at the cued test (Ctrl: cue baseline $=1.2 \pm 0.5 \%$, cue test $=28 \pm 8.0 \%$; no-inhib $(\gamma 2)$ : cue baseline $=2.7 \pm 1.1 \%$, cue test $=27 \pm 6 \%$; cue test: $p=0.95$ ), and we confirmed the absence of phenotype in the contextual test (Ctrl: context baseline $=2.1 \pm 0.5 \%$, context test $=23 \pm 7 \%$; no-inhib $(\gamma 2)$ : context baseline $=2.7 \pm 1.0 \%$, context test $=18 \pm 6 \%$; context test: MW $p=$ 1.00; Fig. $5 B, C$ ). It should be noted that these results differ from those presented in Figure 4; we hypothesize that this difference arises either by the delayed aspects of the cue testing presented above, or, more probably, by the variability in WT behavior and sampling (Button et al., 2013).

To further clarify these contrasting results, we used another mouse line in which PCs receive no inhibitory inputs, an effect obtained by selectively ablating the $\mathrm{K}-\mathrm{Cl}$ cotransporters, KCC type 2 and 3, in PCs (Seja et al., 2012). With these no-inhib(KCC) mice, we performed the exact same experimental protocol as presented in Figure 4, and we observed no deficits in either context memory retention (Ctrl: context baseline $=7.0 \pm 1.6 \%$, context test $=49.2 \pm 8.0 \%$; no-KCC: context baseline $=5.0 \pm 2.0 \%$, context test $=43.7 \pm 6.7 \%$; context test: $p=0.60)$ nor in cue memory retention (Ctrl: cue baseline $=1.8 \pm 0.7 \%$, cue test $=37.7 \pm$ 9.9\%; no-inhib(KCC): cue baseline = $1.2 \pm 0.8 \%$, cue test $=22.6 \pm 7.8 \%$; cue test: MW $p=0.17$; Fig. $5 E, F)$.

Notably, our results are inconsistent with previous studies that demonstrated an involvement of PF-PC plasticity and MLI-PC transmission in a modified cued fear learning and retention protocol (Sacchetti et al., 2004; Scelfo et al., 2008). Therefore, we subjected new groups of mice to the exact same "Torino" cued fear conditioning protocol described in the lit-
A

DAY 1: training, cage A DAY 2: cue test, cage B DAY 3: context test, cage A
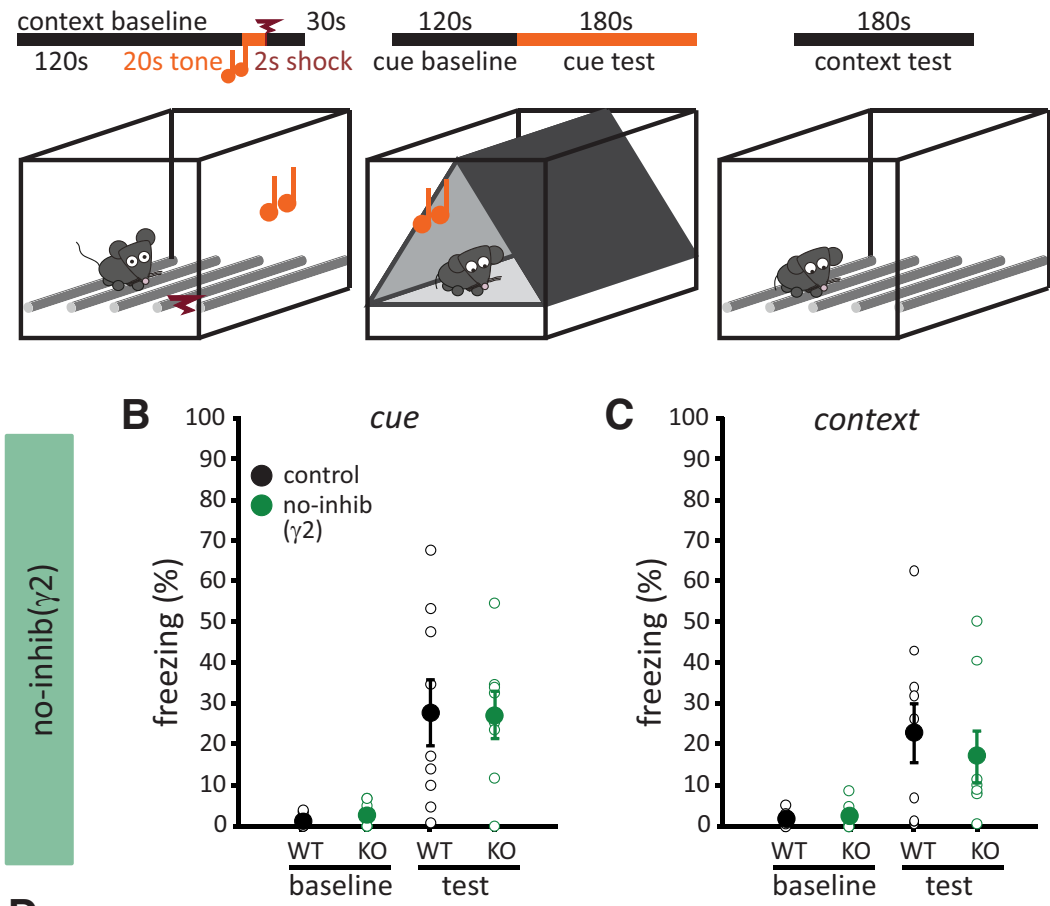

D

DAY 1: training, cage A DAY 2: context test, cage A DAY 3: cue test, cage B
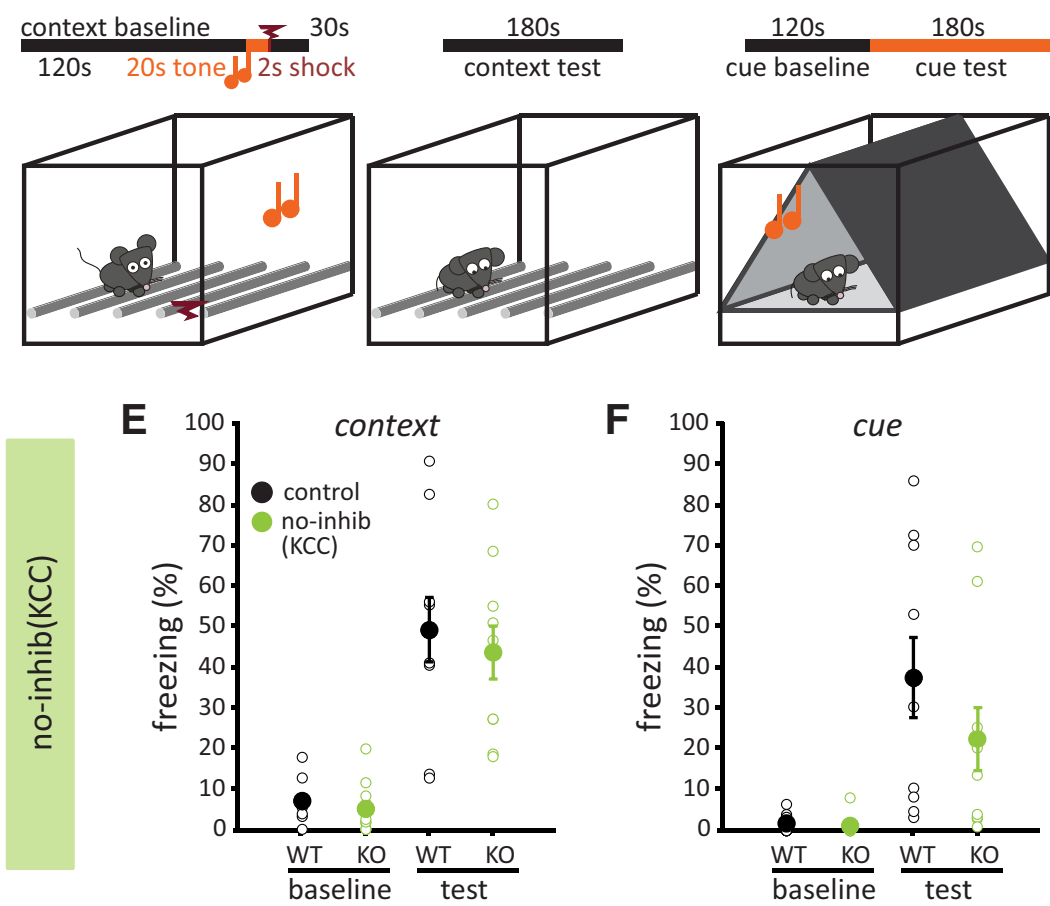

Figure 5. Classic fear conditioning in different mutants lacking inhibition on Purkinje cells. $\boldsymbol{A}$, Graphical representation of the classic fear conditioning task as in Figure 4A, but with inverted cued (day2) and contextual (day 3 ) testing. $\boldsymbol{B}$, Time spent freezing by L7- $\gamma 2$ mice [no-inhib $(\gamma 2), n=8$ ] and their control littermates $(n=9)$ during the cued baseline and test periods (day 2) in Cage B. C, Time spent freezing by the same L7- $\gamma 2$ mice (KO and Ctrl) in Cage A on day 1 (context baseline) and on day 3 (context test). $\boldsymbol{D}$, Similar to Figure 4A. $\boldsymbol{E}$, Time spent freezing by L7-KCC2 mice [no-inhib(KCC), $n=10$ ] and their control littermates $(n=10)$ during the context baseline period (day 1) and the context test (day 2) in Cage A. F, Time spent freezing by the same L7-KCC2 mice ( $\mathrm{KO}$ and $\mathrm{Ctrl}$ ) in Cage B on day 3 during cue baseline and test. Open circles represent individual data points; filled circles are mean \pm $\mathrm{SEM} ; p$ values are indicated in the main text. 
A
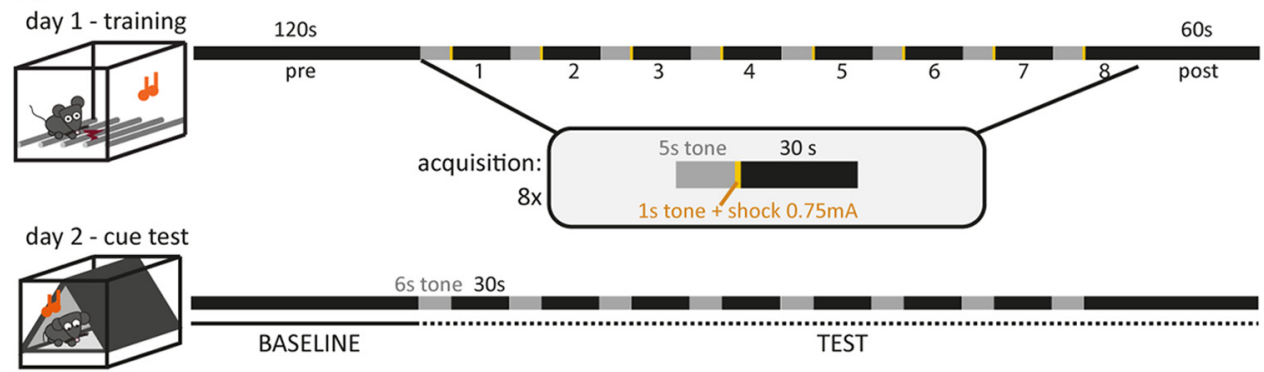

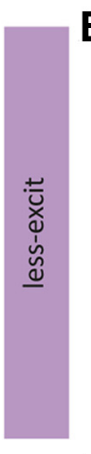

B

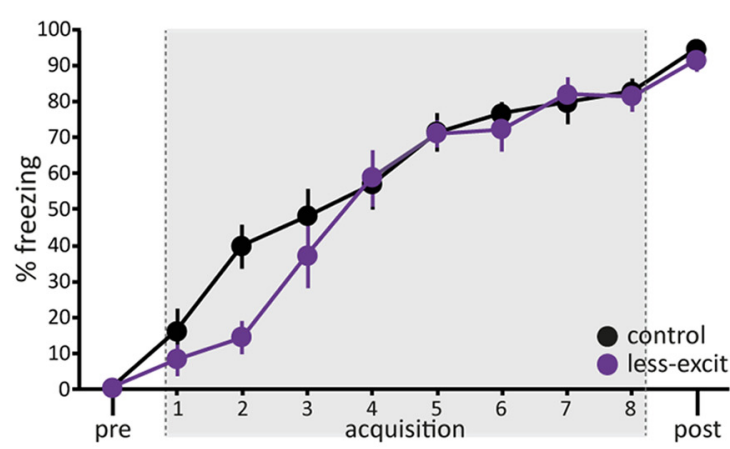

D

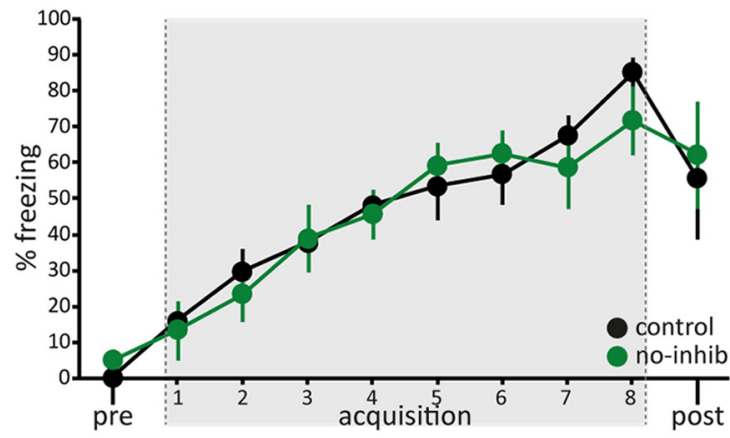

F

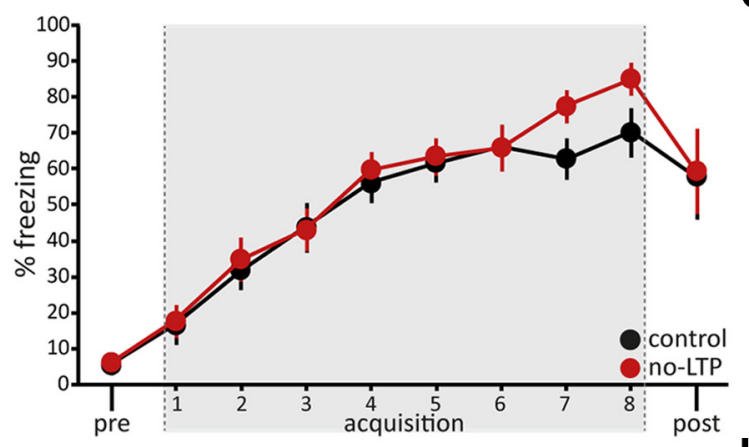

H

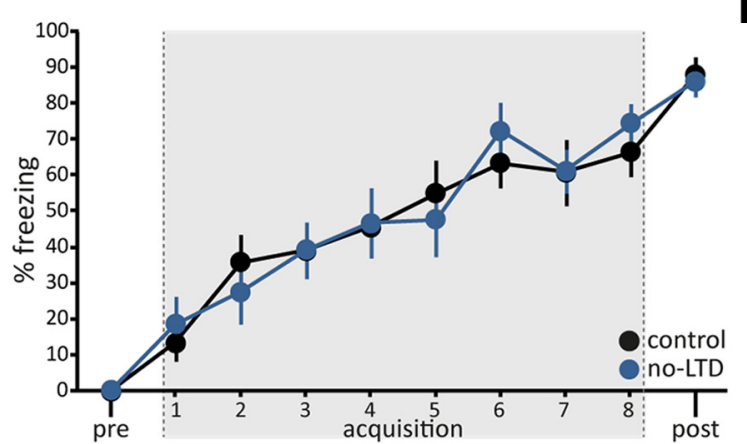

C

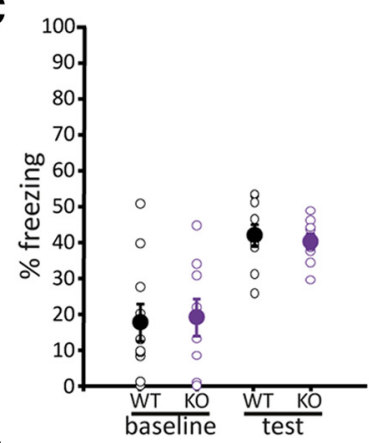

E

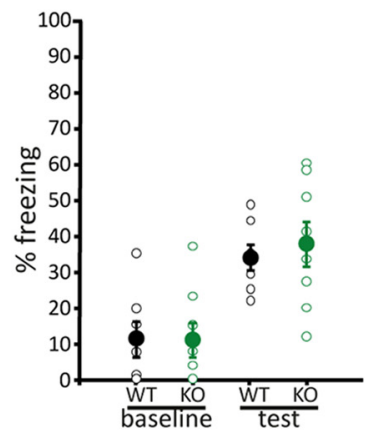

G
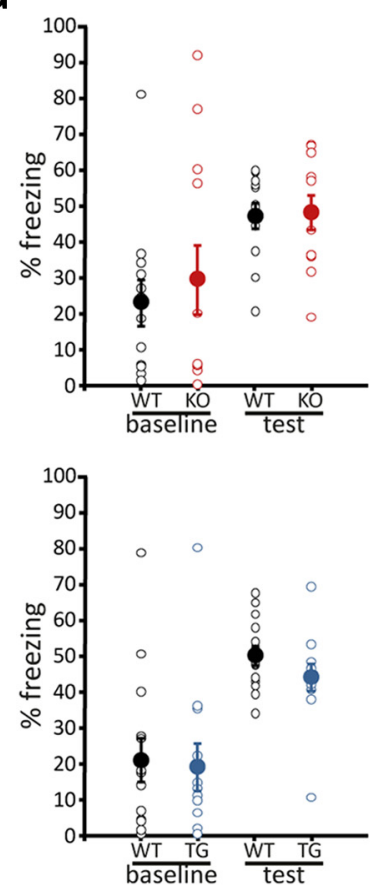

Figure 6. Cued fear conditioning, Torino protocol. A, Graphical representation of the Torino fear conditioning task. On day 1, mice were placed in cage A and left free to explore it for $120 \mathrm{~s}$ (baseline). Eight blocks (acquisition) consisting of $5 \mathrm{~s}$ tone plus $1 \mathrm{~s}$ tone and foot shock followed by $30 \mathrm{~s}$ rest; after 60 additional seconds (post) the mice were put back in the home cage. 0 n day two the mice were place in a different chamber (Cage B) and subjected to the same protocol without the foot shock. The first $120 \mathrm{~s}$ served as cue baseline, (Figure legend continued.) 
Table 7. Fear conditioning quantification, Torino protocol

\begin{tabular}{|c|c|c|c|}
\hline Less-excit ( $\alpha 6$ Cacna1a) & \multicolumn{3}{|c|}{ Repeated-measures ANOVA WT vs KO } \\
\hline \multirow[t]{2}{*}{ Day 1 training } & 0.11 & & \\
\hline & $\mathrm{WT}, n=10$ & $\mathrm{~K} 0, n=9$ & $t$ test \\
\hline Day 2 baseline (\%) & $17.6 \pm 5.2$ & $19.0 \pm 5.0$ & 0.85 \\
\hline Day 2 test (\%) & $41.6 \pm 2.9$ & $40.0 \pm 2.0$ & 0.67 \\
\hline Day 2 baseline vs test & 0.00 & 0.00 & \\
\hline No-inhib (L7- $\gamma 2)$ & \multicolumn{3}{|c|}{ Repeated-measures ANOVA WT vs KO } \\
\hline \multirow[t]{2}{*}{ Day 1 training } & 0.85 & & \\
\hline & WT, $n=7$ & $\mathrm{~K} 0, n=8$ & $t$ test \\
\hline Day 2 baseline (\%) & $11.1 \pm 4.9$ & $10.8 \pm 4.7$ & 0.97 \\
\hline Day 2 test (\%) & $33.7 \pm 3.7$ & $37.4 \pm 6.2$ & 0.62 \\
\hline Day 2 baseline vs test & 0.00 & 0.00 & \\
\hline No-LTP (L7-PP2B) & \multicolumn{3}{|c|}{ Repeated-measures ANOVA WT vs KO } \\
\hline \multirow[t]{2}{*}{ Day 1 training } & 0.25 & & \\
\hline & WT, $n=12$ & $\mathrm{~K} 0, n=12$ & $M W / t$ test \\
\hline Day 2 baseline $(\%)$ & $22.8 \pm 6.4$ & $29.1 \pm 9.4$ & 0.91 \\
\hline Day 2 test (\%) & $46.7 \pm 3.5$ & $47.8 \pm 4.7$ & 0.86 \\
\hline Day 2 baseline vs test & 0.00 & 0.06 & \\
\hline No-LTD (L7-PKCi) & \multicolumn{3}{|c|}{ Repeated-measures ANOVA WT vs TG } \\
\hline \multirow[t]{2}{*}{ Day 1 training } & 0.46 & & \\
\hline & WT, $n=14$ & $\mathrm{TG}, n=12$ & $M W / t$ test \\
\hline Day 2 baseline (\%) & $20.5 \pm 6.0$ & $18.7 \pm 6.5$ & 0.76 \\
\hline Day 2 test $(\%)$ & $49.4 \pm 3.8$ & $43.3 \pm 3.8$ & 0.24 \\
\hline Day 2 baseline vs test & 0.00 & 0.00 & \\
\hline
\end{tabular}

Mean values \pm SEM of the percentage of time spent freezing during cued testing (day 1 baseline and day 2 test; Fig. $6 \mathrm{~A}$; see Materials and Methods for protocol details) for the four mouse lines. Statistical differences between genotypes (KO/TG vs WT) for the acquisition curve (day 1, training) were calculated with an ANOVA for repeated measures test. Statistical differences for baseline and test between genotypes (KO/TG vs WT) and within genotypes (successfulness of the test, i.e... most time spent freezing during test compared with baseline periods) were calculated with a Student's $t$ test for normally-distributed data (regular font) or with a Mann-Whitney test for non-normally distributed data (MW; italic font).

erature (Sacchetti et al., 2004; Fig. 6A; see Materials and Methods). Yet again, we found no significant differences between genotypes in any of the mutant lines, neither during acquisition (all $p>0.11$, repeated measures ANOVA) nor in the retention of the fear memory (tested 24 h later, all $p>0.24$; Fig. 6; Table 7).

Summarizing the fear conditioning results: (1) we found no evidence of alterations in contextual fear conditioning using any of the cerebellar mutants; (2) we detected a phenotype in classical cued fear conditioning in one group of no-inhib $(\gamma 2)$, but we failed to replicate this finding either in a second group of no$\operatorname{inhib}(\gamma 2)$ for which the order of cued and contextual experiments was reversed or in a third group of no-inhib $(\gamma 2)$ for which we used the Torino protocol rather than the conventional protocol; and (3) we failed to detect a cued fear conditioning phenotype in the no-inhib(KCC) animals, which suffer from

\section{$\leftarrow$}

(Figure legend continued.) while the rest of the protocol formed the test period. The time spent by the mice freezing was taken as a measure of fear. $\boldsymbol{B}$, Percentage of time spent freezing by $\alpha 6$-Cacna1a mice (less-excit, $n=9)$ and their control littermates $(n=10)$ during the cued acquisition phase on day 1 (Cage A). C, Time spent freezing by the same $\alpha 6$-Cacna 1a mice (KO and (trl) in Cage $B$ on day 2 during baseline and test. $\boldsymbol{D}, \boldsymbol{E}$, Similar to $\boldsymbol{B}, \boldsymbol{C}$ for $\mathrm{L7}-\gamma 2$ mice (no-inhib, $n=8$ ) and their control littermates $(n=7) . \boldsymbol{F}, \mathbf{G}$, Similar to $\boldsymbol{B}, \boldsymbol{C}$ for L7-PP2B mice (no-LTP, $n=12$ ) and their control littermates $(n=12)$. $\boldsymbol{H}, \boldsymbol{I}$, Similar to $\boldsymbol{B}, \boldsymbol{C}$ for L7-PKCi mice (no-LTD, $n=12$ ) and their control littermates $(n=14)$. Open circles represent individual data points; filled circles are mean $\pm S E M ; p$ values are indicated in the main text and Table 7 . another mutation that causes a similar cellular phenotype as the no-inhib $(\gamma 2)$ mice.

\section{Prefrontal functions of cerebellar mutants showed no alterations}

In nonhuman primates the cerebellum has been shown to be reciprocally connected with the prefrontal cortex, which is believed to be involved in working memory and decision-making (Strick et al., 2009). We therefore decided to further analyze specific behavioral phenotypes during the Morris watermaze and cued fear conditioning task that may depend on prefrontal cortical processing.

Based upon studies which indicated that the swimming path of mice across the watermaze to the platform depends on prefrontal processing (Petrosini et al., 1998; Leggio et al., 2000; Burguière et al., 2005, 2010; Rochefort et al., 2011), we performed a path analysis of the watermaze probe trials to characterize their search for the platform location. We focused on the probe trial at day 8 (when all mice showed learning), and we analyzed the periods both before and after the mouse had reached the trained platform position. In the before epochs, no difference was detected for any mouse line in the time needed to reach the platform position, the distance swam or the deviation from the optimal path (which was set as a straight line from the starting point to the platform; Fig. 7A; see Materials and Methods for details). In addition, the relative periods of time the animals spent in the rectangular zone surrounding the optimal path (direct zone), the circular zone including the platform position (circling zone), and the narrow circle along the wall of the pool (thigmotaxic zone) before they reached the platform were similar among the different genotypes in that all lines of mice tended to spend most time in the direct zone, followed by the circling one (Fig. 7; Table 8; for zone direct all $p>0.19$ ). Regarding the after epochs, we calculated for each mouse how much time was spent in the zone around the platform position (target zone) after having reached it, and how much time was spent in a zone of equal size at the opposite side of the pool (opposite zone; Fig. 7C). All mice showed a marked preference for the target zone and no significant difference between genotypes was detected (all $p>0.35$ ) implying that they had similar levels of perseverance (Fig. 7; Table 8). However, there were two secondary variables for the no-LTP mice that did provide a significant difference: these mutants spent less time than their control littermates in the circling zone during the before epoch and in the opposite zone during the after epoch $(p=0.04$ and $0.03, \mathrm{MW})$. Even so, the no-LTP mice did not differ in the periods of time spent in the direct and target zone (which are the main parameters to characterize an optimal strategy) nor in the amount of time used to locate the platform, the total distance traveled, or the integrated deviation from optimal path. We therefore conclude that their overall performance did not meaningfully differ from the one of their control littermates.

To investigate whether cerebellar processing may contribute to the formation of working memory, which may also depend on the prefrontal cortex (Spitzer et al., 2013), we investigated the level of fear extinction (Fig. 8). If animals are repeatedly given non-reinforced CS presentations, CS-evoked fear responses become progressively diminished. This form of active extinction has been shown to be dependent upon intact working memory (Falls et al., 1992; Carter et al., 2003; Pape and Pare, 2010). Using this protocol we found no difference among genotypes for the less-excit, no-inhib, and no-LTP mutants ( $p$ values: $0.30,0.22$, and 0.40, respectively; repeated-measures ANOVA), whereas the no-LTD animals showed a significantly faster rate of extinction 

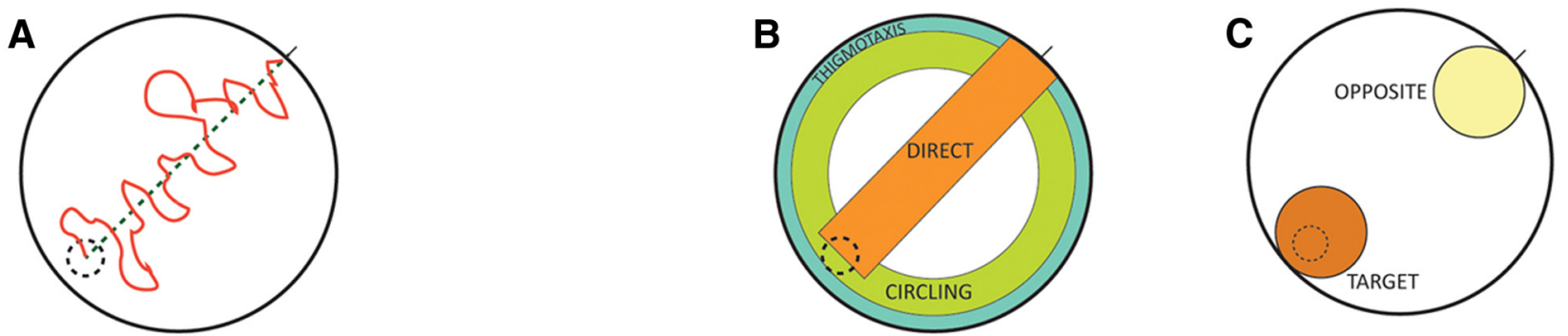
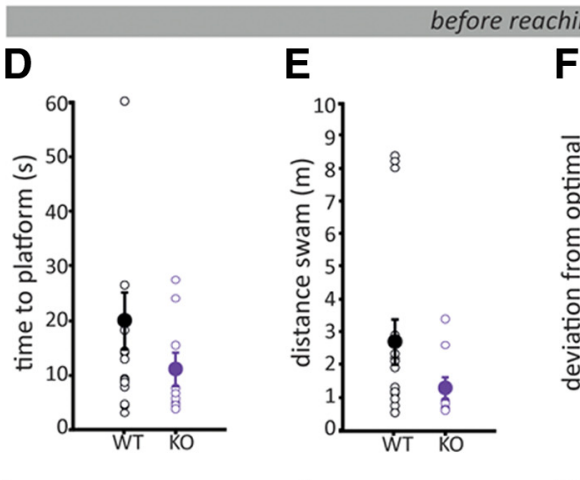

I

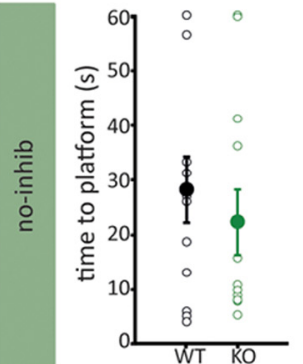

N
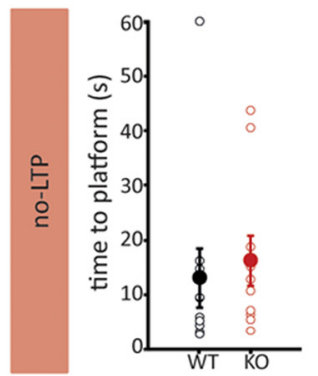

S

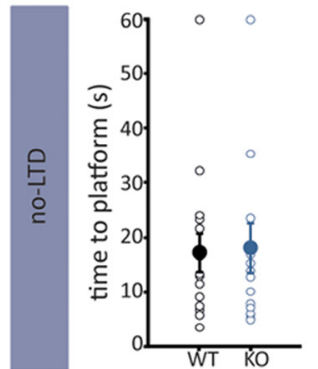

J

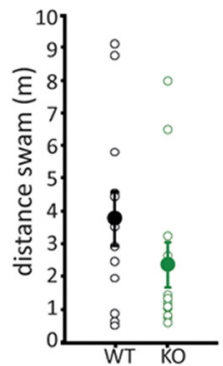

0

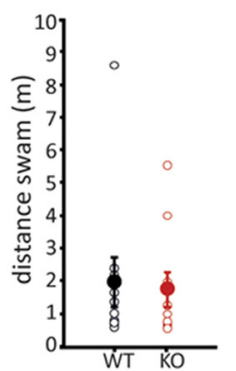

T

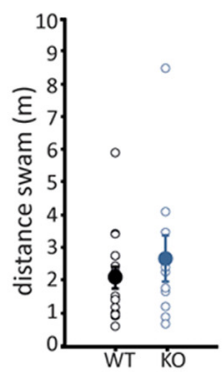

\section{$\mathbf{F}$}

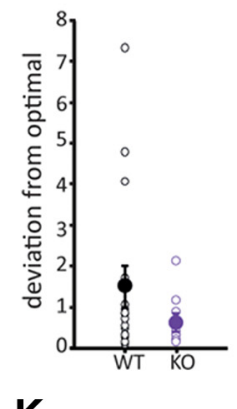

K

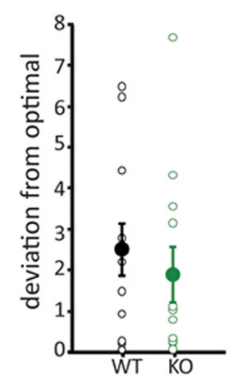

P

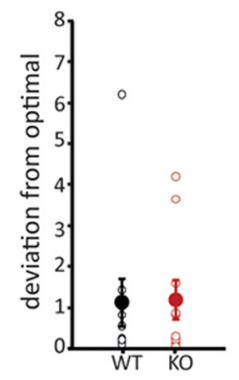

U

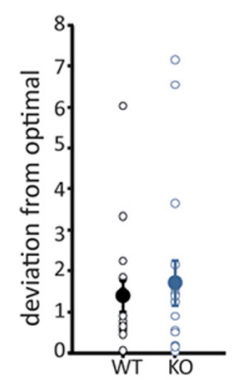

G
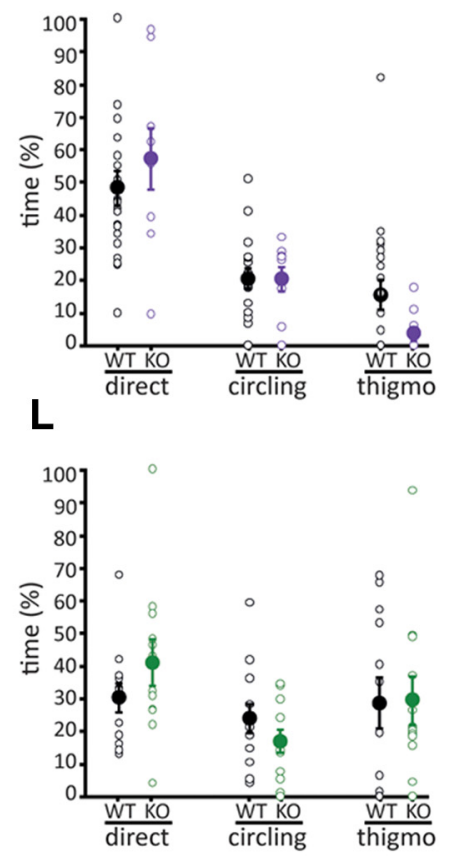

Q
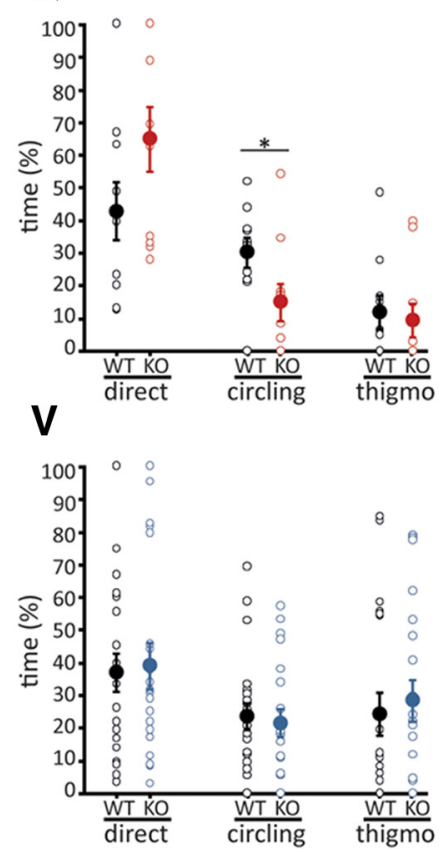

after reaching platform position

H
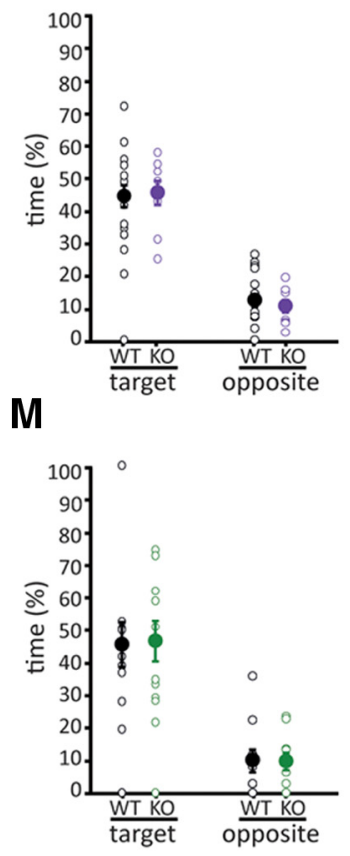

R
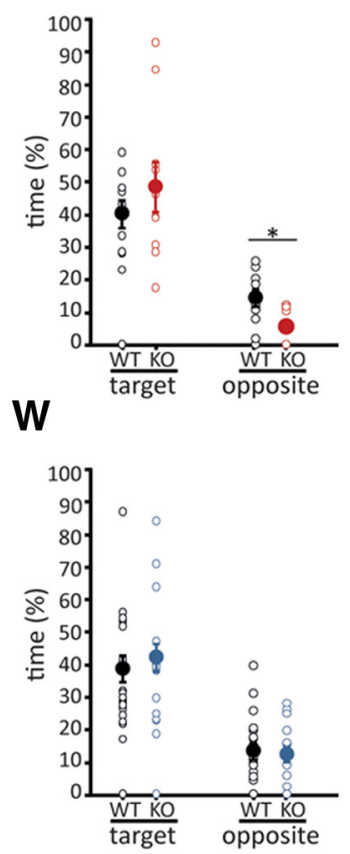

Figure 7. Watermaze path analysis: strategy to locate the platform during probe trial day 8. A, Graphical representation of the start position (black line), platform position (dotted circle), optimal path to reach the platform position (dotted line), and deviation from the optimal path (red line). $\boldsymbol{B}$, Graphical representation of the three zones (direct, circling, and thigmotaxis) in which we divided the pool during the before period. The time spent by the mice in each zone was calculated as a measure of their searching strategy. C, Graphical representation of the two circular zones (target and opposite) in which we divided the pool during the after epoch (from the moment in which they crossed the platform position for the first time to the end of the task). The time spent by the mice in each zone was calculated as a measure of their certainty about the platform position. $\boldsymbol{D}-\boldsymbol{F}$, Time to find the platform (D), total length of the path (distance swam) (E), and (Figure legend continued.) 
than controls ( $p=0.01$, repeated-measures ANOVA; Fig. $8 E$ ). Indeed, when we repeated this test with a second independent group of no-LTD mice, a nonsignificant trend toward more rapid extinction was observed (WT, $n=5$; no-LTD, $n=5 ; p=0.07$, data not shown).

\section{Cerebellar mutants did not show gross motor impairment in open field or rotarod test}

To examine the extent to which the cognitive and emotional tests described above might have been influenced by differences in cerebellar motor coordination, we investigated general motor functioning in the four lines of mice. During exploration of the open-field arena, all mice displayed normal locomotor activity (Fig. 9; Table 9). Moreover, analysis of the time spent in the center versus periphery of the open field arena (for time spent in the inner zone, all $p>0.40$ ) confirmed that there was no indication of a prominent difference in anxiety control (Fig. 9; Table 9). On the rotarod, only the no-LTP mouse line showed a significant impairment (repeated-measures ANOVA $p$ values: less-excit $=$ 0.70 , no-inhib $=0.25$, no-LTP $=0.00$, no-LTD $=0.59$; Fig. 10$)$.

Together with the swimming behavior analysis in the watermaze test, these data indicate that the specific genetic perturbations had little or no effect on the animals' ability to walk and explore a novel arena, despite consistent impairments in their fine motor coordination as expected from cerebellar-targeting mutations (De Zeeuw et al., 1998; Wulff et al., 2009; Schonewille et al., 2010; Galliano et al., 2013).

To summarize our dataset more generally, without applying any correction for multiple testing we found that of the $36 \mathrm{com}$ parisons of motor measures, 10 were statistically significant (28\%), whereas of the 154 comparisons of cognitive/emotional measures only 5 were statistically significant (4\%). If we apply a Bonferroni correction to our dataset (which consists of $190 \mathrm{com}-$ parisons), the significance threshold decreases to 0.0003 , and only three motor comparisons remain statistically significant (L7-PP2B rotarod and swimming performance on day 8). Thus these results demonstrate a very limited, if at all consistent, influence of these cerebellar-specific mutations on cognitive and emotional behavior in mice.

\section{Discussion}

Deficits in cognitive learning tasks have been shown for spontaneous cerebellar mouse mutants, such as Lurcher, Hotfoot, Nervous, Staggerer, and pcd (Lalonde and Strazielle, 2003) as well as in the PC-specific KO of Tsc1, which has been presented as a model for autism, because of its socially impaired and repetitive behavior (Tsai et al., 2012). However, interpreting cognitive and emotional behavioral deficits in animal models of cerebellar impairment often remains difficult due to severe motor impairments. In addition, many of the mutant strains examined in

\footnotetext{
(Figure legend continued.) deviation from the optimal path $(\boldsymbol{F})$ of $\alpha 6$-Cacna1a mice (less-excit, $n=9$ ) and their control littermates $(n=20)$ calculated from the start of the task (i.e., probe trial day 8) to the moment in which they crossed the platform position (before epoch). $\mathbf{G}$, Time spent in the different zones by the same $\alpha 6$-Cacna1a mice (KO and (trl) during the before epoch. $\boldsymbol{H}$, Time spent in the different zones by the same $\alpha 6$-Cacna1a mice (K0 and (trl) calculated from the end of the before epoch to end of the probe trial day 8 task (after epoch). $I-M$, Similar to $\boldsymbol{D}-\boldsymbol{H}$ for L7- $\boldsymbol{\gamma} 2$ mice (no-inhib, $n=12$ ) and their control littermates $(n=12) . \boldsymbol{N}-\boldsymbol{R}$, Similar to $\boldsymbol{D}-\boldsymbol{H}$ for L7-PP2B mice (no-LTP, $n=10$ ) and their control littermates $(n=10)$. $\mathbf{S}-\boldsymbol{W}$, Similar to $\boldsymbol{D}-\boldsymbol{H}$ for L7-PKCi mice (no-LTD, $n=22$ ) and their control littermates $(n=22)$. Open circles represent individual data points; filled circles are mean $\pm S E M ; ~ p ~ v$ values are indicated in the main text and Table 8.
}

Table 8. Watermaze: probe trial day 8 path analysis

\begin{tabular}{|c|c|c|c|}
\hline Less-excit ( $\alpha 6$ Cacna1a) & WT, $n=20$ & $\mathrm{~K} 0, n=9$ & $M W / t$ test \\
\hline Mice who reached $\mathrm{P}$ position & $77 \%$ & $100 \%$ & \\
\hline \multicolumn{4}{|l|}{ Before reaching P position } \\
\hline Time to platform (s) & $19.8 \pm 4.8$ & $10.9 \pm 3.0$ & 0.28 \\
\hline Distance traveled $(\mathrm{m})$ & $2.7 \pm 0.7$ & $1.3 \pm 0.3$ & 0.26 \\
\hline Deviation from optimal path & $1469.9 \pm 468.8$ & $572.8 \pm 218.1$ & 0.30 \\
\hline Time in zone direct (\%) & $48.3 \pm 5.3$ & $57.3 \pm 9.2$ & 0.38 \\
\hline Time in zone circling (\%) & $20.6 \pm 3.2$ & $20.4 \pm 3.7$ & 0.98 \\
\hline Thigmotaxis (\%) & $15.5 \pm 4.6$ & $3.8 \pm 2.1$ & 0.13 \\
\hline \multicolumn{4}{|l|}{ AFTER reaching P position } \\
\hline Time in zone target (\%) & $44.1 \pm 3.4$ & $45.0 \pm 3.7$ & 0.87 \\
\hline Time in zone opposite (\%) & $12.4 \pm 2.0$ & $10.4 \pm 1.9$ & 0.54 \\
\hline No-inhib (L7- $\gamma 2)$ & WT, $n=12$ & $\mathrm{~K} 0, n=12$ & $M W / t$ test \\
\hline Mice who reached $P$ position & $83 \%$ & $83 \%$ & \\
\hline \multicolumn{4}{|l|}{ Before reaching $P$ position } \\
\hline Time to platform (s) & $28.3 \pm 6.1$ & $22.1 \pm 6.1$ & 0.56 \\
\hline Distance traveled (m) & $3.9 \pm 0.8$ & $2.5 \pm 0.7$ & 0.23 \\
\hline Deviation from optimal path & $2527.8 \pm 635.8$ & $1926.3 \pm 676.2$ & 0.53 \\
\hline Time in zone direct (\%) & $30.2 \pm 4.4$ & $41.1 \pm 7.0$ & 0.20 \\
\hline Time in zone circling (\%) & $24.0 \pm 4.6$ & $17.0 \pm 3.5$ & 0.24 \\
\hline Thigmotaxis (\%) & $28.7 \pm 7.9$ & $29.5 \pm 7.3$ & 0.93 \\
\hline \multicolumn{4}{|l|}{ After reaching $P$ position } \\
\hline Time in zone target (\%) & $45.5 \pm 6.9$ & $46.5 \pm 6.2$ & 0.82 \\
\hline Time in zone opposite (\%) & $10.2 \pm 3.5$ & $10.0 \pm 2.7$ & 0.82 \\
\hline No-LTP (L7-PP2B) & WT, $n=10$ & $\mathrm{~K} 0, n=10$ & $M W / t$ test \\
\hline Mice who reached $\mathrm{P}$ position & $90 \%$ & $100 \%$ & \\
\hline \multicolumn{4}{|l|}{ Before reaching P position } \\
\hline Time to platform (s) & $13.1 \pm 5.4$ & $17.7 \pm 4.8$ & 0.26 \\
\hline Distance traveled (m) & $2.0 \pm 0.8$ & $1.9 \pm 0.6$ & 0.71 \\
\hline Deviation from optimal path & $1115.2 \pm 579.8$ & $1322.4 \pm 514.6$ & 0.88 \\
\hline Time in zone Direct (\%) & $42.8 \pm 8.8$ & $60.9 \pm 10.1$ & 0.14 \\
\hline Time in zone Circling (\%) & $30.3 \pm 4.6$ & $16.7 \pm 5.9$ & 0.04 \\
\hline Thigmotaxis (\%) & $11.9 \pm 5.0$ & $10.5 \pm 5.5$ & 0.42 \\
\hline \multicolumn{4}{|l|}{ After reaching $P$ position } \\
\hline Time in zone target (\%) & $40.1 \pm 4.1$ & $43.5 \pm 6.5$ & 0.66 \\
\hline Time in zone opposite (\%) & $14.4 \pm 2.6$ & $6.4 \pm 2.0$ & 0.03 \\
\hline No-LTD (L7-PKCi) & WT, $n=22$ & $\mathrm{TG}, n=22$ & $M W / t$ test \\
\hline Mice who reached $P$ position & $91 \%$ & $91 \%$ & \\
\hline \multicolumn{4}{|l|}{ Before reaching P position } \\
\hline Time to platform (s) & $17.4 \pm 3.4$ & $16.9 \pm 3.4$ & 0.87 \\
\hline Distance traveled $(\mathrm{m})$ & $2.1 \pm 0.4$ & $2.4 \pm 0.5$ & 0.80 \\
\hline Deviation from optimal path & $1351.1 \pm 332.5$ & $1525.8 \pm 413.0$ & 0.89 \\
\hline Time in zone direct (\%) & $40.9 \pm 6.1$ & $39.0 \pm 6.3$ & 0.74 \\
\hline Time in zone circling (\%) & $23.1 \pm 3.9$ & $21.3 \pm 3.8$ & 0.61 \\
\hline Thigmotaxis (\%) & $22.2 \pm 6.1$ & $28.6 \pm 5.8$ & 0.30 \\
\hline \multicolumn{4}{|l|}{ After reaching $P$ position } \\
\hline Time in zone target (\%) & $37.3 \pm 3.7$ & $42.4 \pm 3.8$ & 0.29 \\
\hline Time in zone opposite (\%) & $13.7 \pm 2.3$ & $12.3 \pm 1.9$ & 0.65 \\
\hline
\end{tabular}

For each mouse line the first row of the table indicates the percentage of individuals who reached the platform (P) position before the end of the $60 \mathrm{~s}$ probe trial. For those mice, in the before epoch mean values \pm SEM of the time needed to reach the platform position, total distance traveled to reach the platform position from the start position, deviation from the optimal path (Fig. 7A shows graphical representation) and percentage of time spent in the three zones (direct, circling, and thigmotaxis; Fig. 7B) are reported for the four mouse lines. Moreover, the percentage of time spent during the after epoch in the target or opposite zone (Fig. 7C) is also reported as mean values \pm SEM for all groups. Statistical differences between genotypes were calculated with a Student's $t$ test for normally-distributed data (regular font) or with a Mann-Whitney test for non-normally distributed data (MW; italic font).

previous studies have suffered from extra-cerebellar impairments, such as degeneration in retina, cochlea, and olfactory bulb, and systems defects in thalamic and mono-aminergic inputs. To minimize these confounders we focused the present study on the cognitive and emotional behavior of four different genetically modified mouse lines, all carrying a cerebellar cell-specific mutation that affects PC physiology and motor learning, but does not 
A

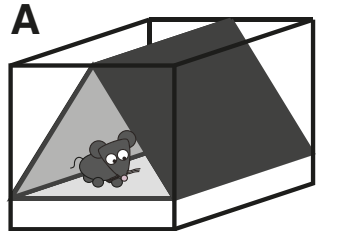

B
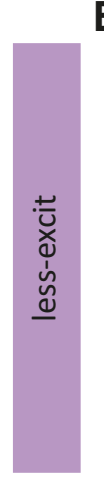

C

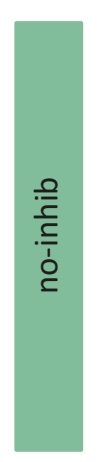

C
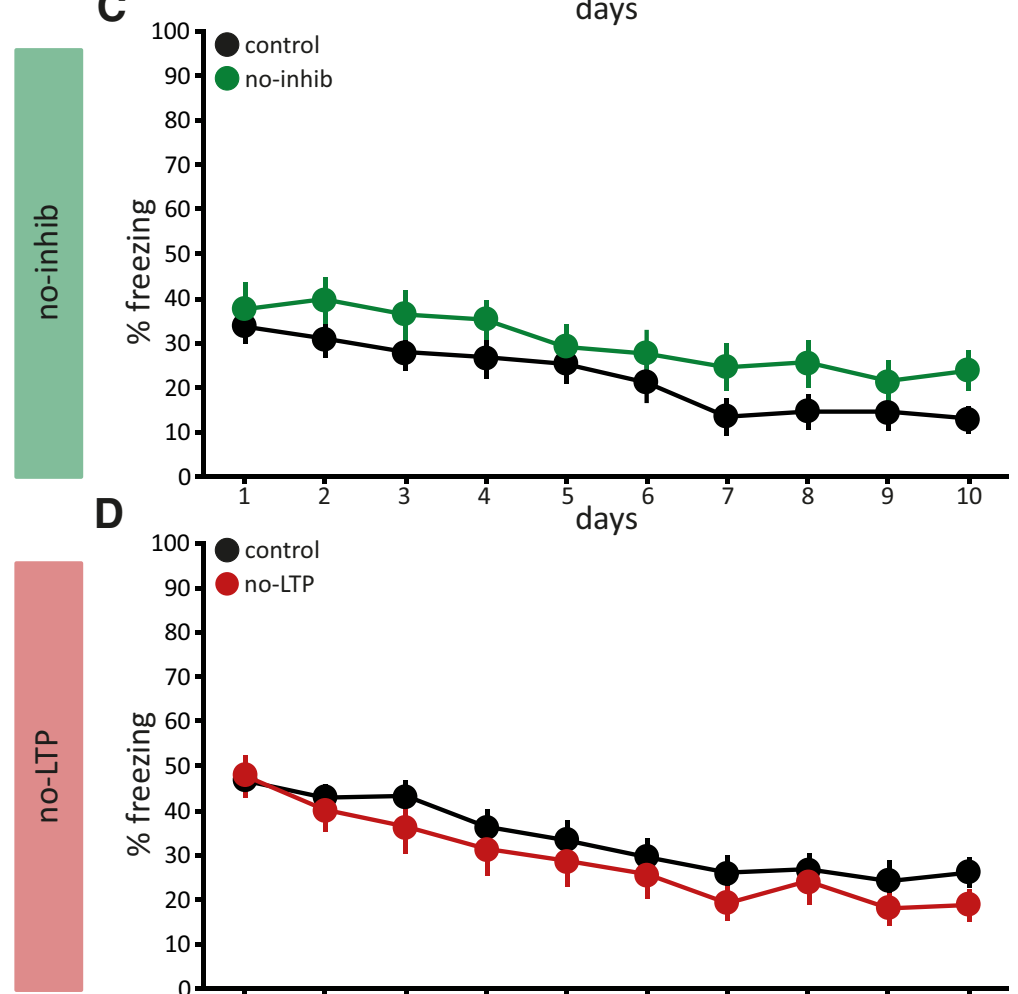

E

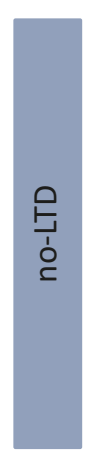

\section{EXTINCTION TEST}

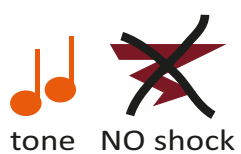

after training,

for 10 consecutive days
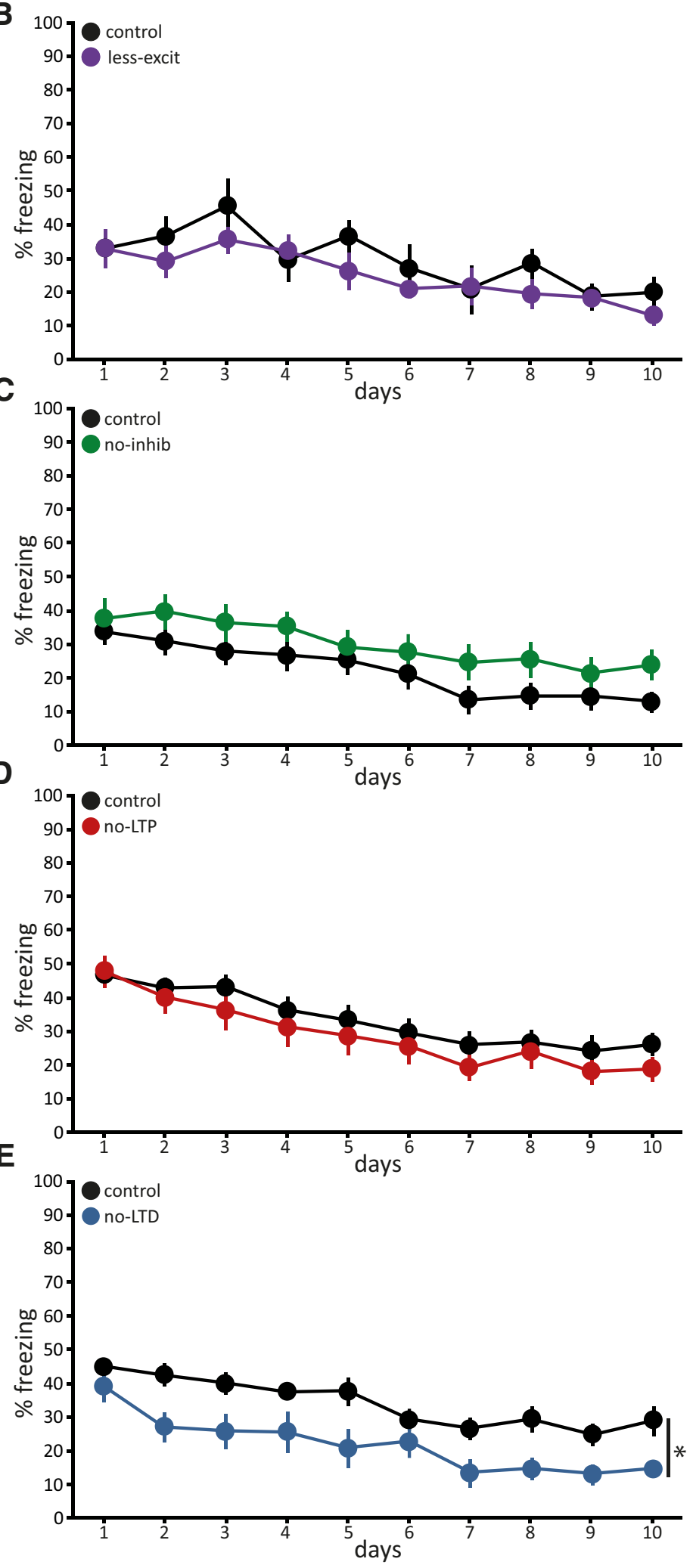

Figure 8. Fear conditioning extinction. $\boldsymbol{A}$, Graphical representation of the fear conditioning extinction task. After either classic or Torino cued training in Cage A, the mice were tested for 10 consecutive days in absence of foot shock in Cage B. The time spent

cause ataxia (De Zeeuw et al., 1998; Wulff et al., 2009; Schonewille et al., 2010; Galliano et al., 2013). We investigated behavior of mice that have impaired neurotransmission at the PF to PC synapse (less-excit mutants) or at the molecular layer interneuron to PC synapse (no-inhib mutants), or that suffer from impaired intrinsic plasticity and long-term potentiation (no-LTP mutants) or long-term depression (no-LTD mutants) at the PF to PC synapse. Whereas the less-excit mutants did not show any deficit in any of the tests on social behavior, spatial navigation or emotional conditioning, each of the other three categories of mouse mutants showed one or two abnormalities in a limited subset of the numerous phenotypes examined. Of the 154 statistical comparisons only 5 showed a significant difference; yet the effect sizes of these differences were all small and obtained without any statistical correction for multiple comparisons. Thus overall, we found little confirmation of cognitive and emotional deficits in our non-ataxic and morphologically intact mouse lines, which suggests that extra-cerebellar influences, morphological disruptions and/or ataxia may be partly or even entirely responsible for the cognitive phenotypes described previously in mice (Lalonde and Strazielle, 2003).

\section{Cognition and emotion in no- inhib mutants}

The L7- $\gamma 2$ mice showed no deficits during social testing or contextual fear conditioning, but subtle abnormalities during some of the Morris watermaze tasks and one of the cued fear conditioning tests (Tables 3-6). L7- $\gamma 2$ mice showed normal spatial navigation learning in that they learned well where the hidden platform was located, but the latency to reach the platform was significantly higher than control littermates during several training days. This difference was coupled to the slower swimming speed and higher resting time, but did not affect their probe trial performance in which we assessed the ability to remember the location of the

$\leftarrow$

by the mice freezing, i.e., the used indication of fear, decreases over time. $\boldsymbol{B}$, Percentage of time spent freezing by $\alpha 6$ Cacna1a mice (less-excit, $n=11$ ) and their control littermates ( $n=10$ ) during the cued test phase on 10 consecutive days. $C$, Similar to $\boldsymbol{B}$ for L7- $\gamma 2$ mice (no-inhib, $n=8$ ) and their control littermates $(n=7)$. $\boldsymbol{D}$, Similar to $\boldsymbol{B}$ for L7-PP2B mice (no-LTP, $n=12$ ) and their control littermates $(n=12)$. $\boldsymbol{E}$, Similar to $\boldsymbol{B}$ for L7-PKCi mice (no-LTD, $n=7$ ) and their control littermates $(n=9)$. Values are mean \pm SEM; asterisks indicate significant differences; $p$ values are indicated in the main text. 
A

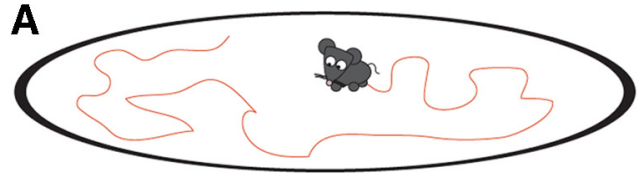

C

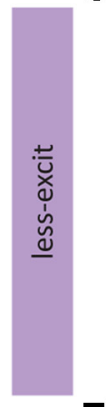

$\mathbf{F}$

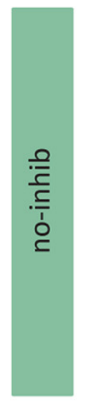

I
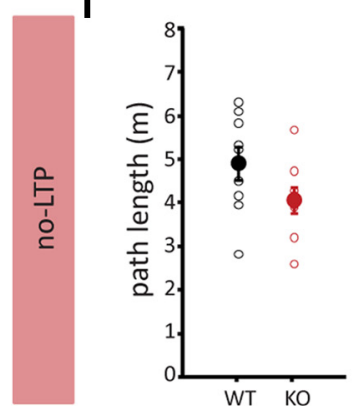

$\mathbf{L}$

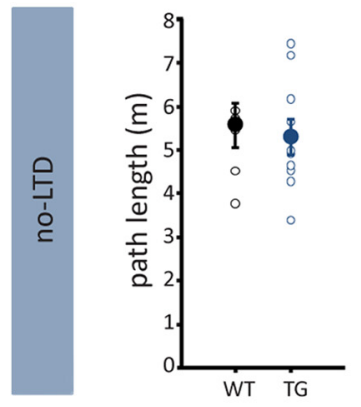

D

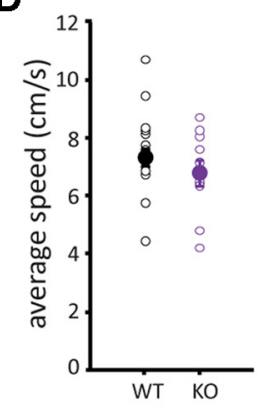

G
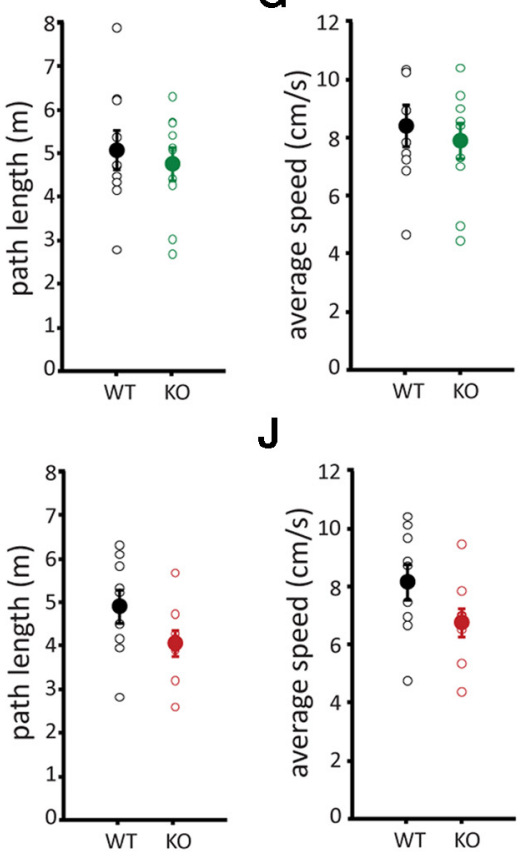

M

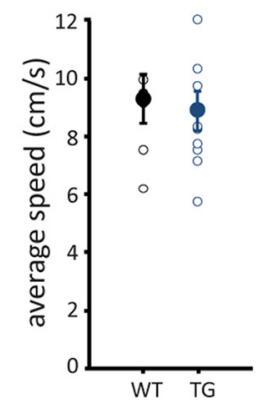

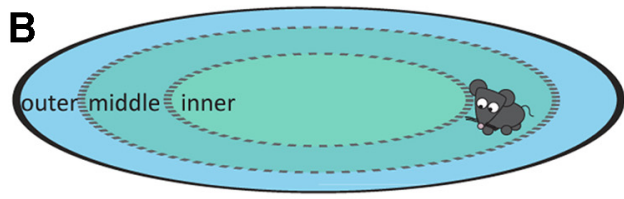

E

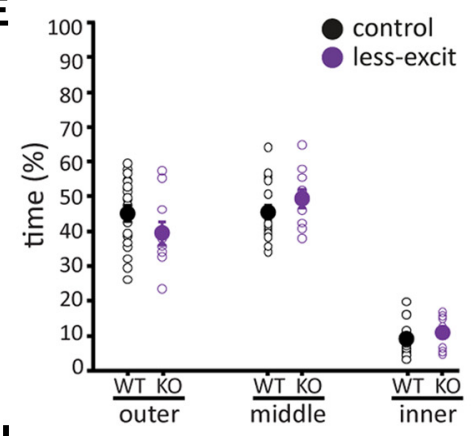

H

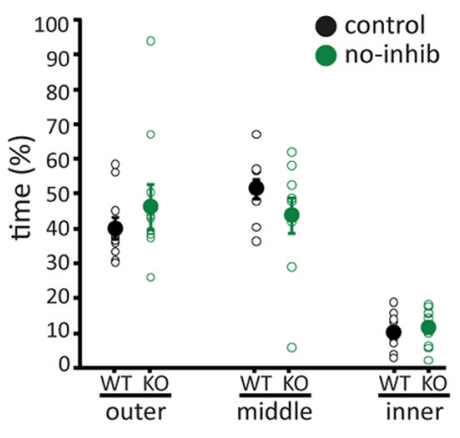

K

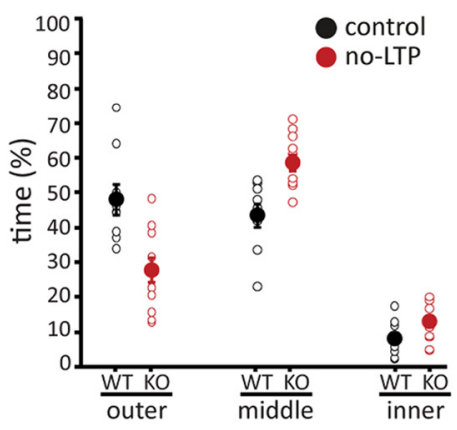

N

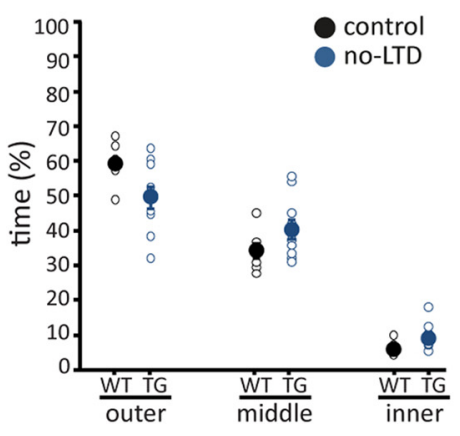

Figure 9. Open field test. $A, B$, Graphical representation of the open field task. Mice were allowed to walk freely in a circular arena for 10 min. During the analysis the arena was divided into three concentric zones (outer, middle, inner), and the percentage of time spent in the zones was taken as an indication of general anxiety (i.e., anxious animals tend to walk only in the outer zone without crossing the arena). $\boldsymbol{C}, \boldsymbol{D}$, Path length and average speed of $\alpha 6$-Cacnala mice (less-excit, $n=10)$ and their control littermates $(n=20)$ in the open field. $\boldsymbol{E}$, Percentage of time spent by $\alpha 6$-Cacna1a mice and their control littermates in the outer, middle, and inner zone. $\boldsymbol{F}-\boldsymbol{H}$, Similar to $\mathbf{C}-\boldsymbol{E}$ for L7- $\boldsymbol{\gamma} \mathbf{2}$ mice (no-inhib, $n=10)$ and their control littermates $(n=10) . \boldsymbol{I}-\boldsymbol{K}$, Similar to $\boldsymbol{C}-\mathbf{E}$ for L7-PP2B mice (no-LTP, $n=$ 10) and their control littermates $(n=9)$. $L-N$, Similar to $C-E$ for L7-PKCi mice (no-LTD, $n=10)$ and their control littermates $(n=7)$. Open circles represent individual data points; filled circles are mean \pm SEM; $p$ values are indicated in the main text and Table 9. 
Table 9. Open field quantification

\begin{tabular}{lccl}
\hline Less-excit $(\alpha 6$ Cacna1a) & WT, $n=20$ & KO, $n=10$ & $t$ test \\
\hline Average speed (cm/s) & $7.3 \pm 0.3$ & $6.8 \pm 0.5$ & 0.31 \\
Path length (m) & $4.4 \pm 1.8$ & $4.1 \pm 0.28$ & 0.31 \\
& & & Pearson $\chi^{2}$ \\
\hline Time in outer zone (\%) & $45.3 \pm 2.2$ & $39.6 \pm 3.3$ & 0.36 \\
Time in middle zone (\%) & $45.6 \pm 1.8$ & $49.5 \pm 2.6$ & 0.32 \\
Time in inner zone (\%) & $9.3 \pm 0.9$ & $10.9 \pm 1.4$ & 0.42 \\
No-inhib (L7- $\gamma 2)$ & WT, $n=10$ & K0, $n=10$ & $t$ test \\
\hline Average speed (cm/s) & $8.4 \pm 0.7$ & $7.9 \pm 0.6$ & 0.58 \\
Path length (m) & $5.0 \pm 0.4$ & $4.7 \pm 0.4$ & 0.58 \\
& & & Pearson $\chi^{2}$ \\
\hline Time in outer zone (\%) & $39.6 \pm 3.2$ & $46.0 \pm 6.5$ & 0.39 \\
Time in middle zone (\%) & $51.0 \pm 2.8$ & $43.0 \pm 5.1$ & 0.33 \\
Time in inner zone (\%) & $9.4 \pm 1.6$ & $10.8 \pm 1.8$ & 0.40 \\
No-LTP (L7-PP2B) & WT, $n=9$ & K0, $n=10$ & $t$ test \\
\hline Average speed (cm/s) & $6.7 \pm 0.6$ & $8.1 \pm 0.4$ & 0.08 \\
Path length (m) & $4.0 \pm 0.4$ & $4.9 \pm 0.3$ & 0.08 \\
& & & Pearson $\chi^{2}$ \\
\hline Time in outer zone (\%) & $48.3 \pm 3.7$ & $28.0 \pm 3.7$ & 0.33 \\
Time in middle zone (\%) & $43.7 \pm 3.4$ & $58.9 \pm 2.3$ & 0.40 \\
Time in inner zone (\%) & $8.0 \pm 1.7$ & $13.1 \pm 1.8$ & 0.40 \\
No-LTD (L7-PKCi) & WT, $n=7$ & TG, $n=10$ & $t$ test \\
\hline Average speed (cm/s) & $9.3 \pm 0.9$ & $8.9 \pm 0.7$ & 0.71 \\
Path length (m) & $5.6 \pm 0.5$ & $5.3 \pm 0.4$ & 0.68 \\
& & & Pearson $\chi^{2}$ \\
\hline Time in outer zone (\%) & $59.6 \pm 2.2$ & $50.0 \pm 3.2$ & 0.46 \\
Time in middle zone (\%) & $34.5 \pm 2.2$ & $40.7 \pm 2.8$ & 0.39 \\
Time in inner zone (\%) & $5.9 \pm 0.7$ & $9.3 \pm 1.1$ & 0.46 \\
\hline & & & \\
\hline
\end{tabular}

Mean values \pm SEM of average walking speed, path length, and percentage of time spent in the different open field zones (outer, inner, middle) for the four mouse lines. Statistical differences were calculated with a Student's $t$ test and with a Pearson $\chi^{2}$ test.

platform. L7- $\gamma 2 \mathrm{KO}$ mice showed a deficit in the cued fear learning in that they showed a decreased level of freezing during the classical cued fear conditioning paradigm following the contextual paradigm. However, the classic cued phenotype was not observed when the test was repeated with a new group of L7- $\gamma 2$ mice. In addition, an independent mouse line with a different genetic mutation (L7-KCC2), but a similar cellular deficit (Seja et al., 2012), successfully learned to associate the cue with the fearful event in the classic test (Fig. 5). Moreover, in contrast with previous investigations performed in rats (Scelfo et al., 2008), cued learning with the Torino protocol was also unimpaired (Fig. 6; Table 7). In fact, our data raise the question whether plasticity in cerebellar interneurons after exposure to a stressful stimulus is necessary and sufficient to explain their freezing response (Liu et al., 2010; Ruediger et al., 2011).

\section{Cognition and emotion in no-LTP mutants}

L7-PP2B mice showed no deficits during social testing or contextual and cued fear conditioning, but we did observe some motor coordination abnormalities during the Morris watermaze and rotarod tasks (Tables 3-5; Fig. 10). Whereas the motor deficits in L7-PP2B mice parallel their decreased performance in compensatory eye movements (Schonewille et al., 2010), our findings with fear conditioning in these animals are in contrast with previous studies from the Strata laboratory reporting involvement of PF-PC LTP in cued fear conditioning in rats

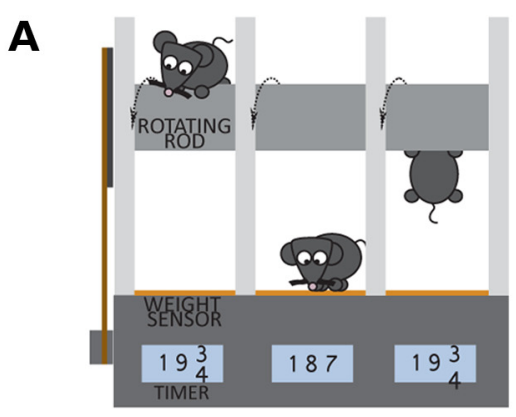

B
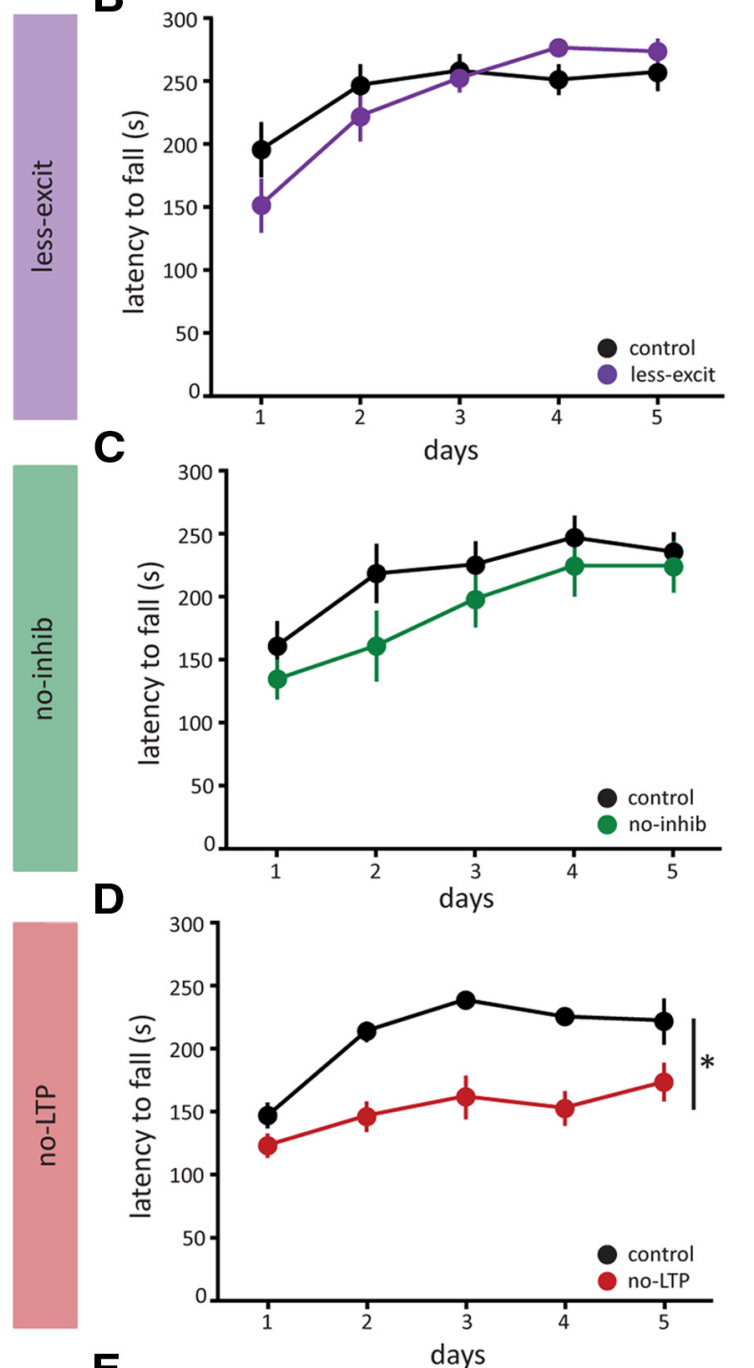

E

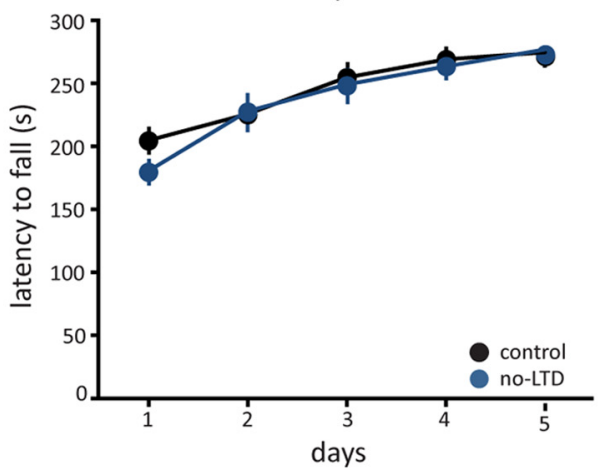

Figure 10. Rotarod test. $\boldsymbol{A}$, Graphical representation of the accelerating rotarod task. Latency times indicate the seconds needed for the mouse either to fall from the rod or to revolve $360^{\circ}$ for three consecutive times. $\boldsymbol{B}$, Rotarod performance over 5 (Figure legend continued.) 
and hotfoot mice (Sacchetti et al., 2004; Zhu et al., 2007). Possibly, the phenotype observed in the hotfoot mice, which suffer from a spontaneous mutation of the Grid2 gene, results in part from a defect in their monoaminergic system modulating the limbic structures required for freezing and/or from their jumping behavior (Draski et al., 1994; Homberg, 2012). In contrast, the absence of a fear conditioning phenotype in L7-PP2B mice is consistent with the fact that we also did not observe abnormalities in the less-excit mice, which also lack PF-PC LTP (Galliano et al., 2013).

\section{Cognition and emotion in no-LTD mutants}

L7-PKCI mice showed no deficits during social testing, standard Morris watermaze tasks, or acquisition of contextual or cued fear conditioning, but we did observe a difference in their rate of extinction of conditioned fear (Fig. 8). Interestingly, these mice tended to extinguish their cued-fear responses faster than controls in two separate and independent, blindly analyzed blocks of experiments. However, whether the lack of PF-PC LTD in the L7-PKCI mice is one of the critical factors in this behavioral phenotype remains to be elucidated, because the less-excit mutants, which suffer from impaired transmission at their PF-PC synapse, also show impaired LTD induction (Galliano et al., 2013), yet failed to replicate this enhanced extinction. Moreover, because PKC can exert multiple functions in Purkinje cells (Gao et al., 2012), we cannot exclude the possibility that other unknown factors contribute to its phenotype. Possibly, PKCmediated cellular processes in Purkinje cells are involved in some forms of nonmotor learning in a similar fashion to the role of PKC (and ERK) signaling in hippocampal and striatal learning (Tronson et al., 2008; Shiflett and Balleine, 2011). Some contribution of a PKC-mediated cellular process in Purkinje cells to nonmotor processing in higher brain regions is supported by a series of studies by the Rondi-Reig laboratory who showed that the performance of L7-PKCi mice during a more complicated, spatial navigation in the dark is suboptimal in terms of path optimization and that the activity of their place cells in the hippocampus is abnormal (Burgueire et al., 2005 and 2010; Rochefort et al. 2011).

\section{Comparative mammalian neuroanatomy}

Considering the emerging and convincing body of evidence regarding human cerebellar patients with cognitive/emotional symptoms (Schmahmann, 2010), we are puzzled by the lack of behavioral deficits observed in our mice. Thus apart from the possibility that the mammalian cerebellum might not be involved in cognitive and/or emotional processing in general, several explanations should be considered.

First, it is possible that there is developmental compensation inside the cerebellar nuclei and/or extra-cerebellar brain circuits to make up for the loss of function in PCs. Such compensations can occur later in development, but also relatively early as most of the genes and promoters involved are expressed from early on (Oberdick, 1994; Jones et al., 2000). Still, even if this process plays a prominent role in our mutants, it remains intriguing that all of

$\leftarrow$

(Figure legend continued.) consecutive training days of $\alpha 6$-Cacna1a mice (less-excit, $n=10$ ) and their control littermates $(n=10)$. C, Similar to $\boldsymbol{B}$ for $\mathrm{L} 7-\gamma 2$ mice (no-inhib, $n=10$ ) and their control littermates $(n=10)$. $\boldsymbol{D}$, Similar to $\boldsymbol{B}$ for L7-PP2B mice (no-LTP, $n=9)$ and their control littermates $(n=10)$. $\boldsymbol{E}$, Similar to $\boldsymbol{B}$ for L7-PKCi mice (no-LTD, $n=13$ ) and their control littermates $(n=10)$. Values are mean \pm SEM; asterisks indicate significant differences; $p$ values are indicated in the main text. them have prominent phenotypes in motor learning and consolidation (Gao et al., 2012), but not in the standard paradigms for cognitive and emotional functions tested here.

Second, the mutations examined here may not have affected the cerebellar output signals severely enough to disrupt the examined behaviors. It should be noted though that within the category of cell-specific mutants without ataxia we have tested the mutants with the most severe phenotypes in motor coordination currently available (for review, see De Zeeuw et al., 2011). These even included mutants, such as the L7-PP2B mutants, which do not only show prominent learning and consolidation deficits, but also mild motor performance deficits in sensitive eye movements tests (Schonewille et al., 2010). Thus, cranking up the severity of cellular deficits an extra level probably would have resulted in mutants with morphological aberrations and signs of ataxia, for which it would have been difficult to interpret the putatively positive phenotypes (Lalonde and Strazielle, 2003).

Third, the tests to which we subjected the animals might not have been sufficiently demanding. For this study we choose to only use standardized behavioral tests that have been widely used and are known to detect phenotypes in mice with mutations affecting the forebrain and limbic system (Elgersma et al., 2002; Kushner et al., 2005; Han et al., 2009). However, because cerebellar processing is particularly well designed to control temporal processing at a high resolution (De Zeeuw et al., 2011), phenotypes might pop up when this ingredient is incorporated in the behavioral task. Similarly, it is possible that more complicated tasks, such as those used by the Rondi-Reig laboratory require a more prominent cerebellar contribution and/or allow a cerebellar phenotype detection when tested with a high sample size (Button et al., 2013).

Last, but not least, one should consider the possibility that the role of the murine cerebellum in cognitive and emotional processing is not well developed. Whereas connections from the cerebellum to the cerebral cortex have been extensively demonstrated in patients, human subjects, nonhuman primates, cats, and rats using lesions, fMRI, transneuronal virus tracing, and conventional anterograde and retrograde tracing (Shinoda et al., 1985; Teune et al., 2000; Ramnani, 2006; Strick et al., 2009; Timmann et al., 2010), no such connectivity studies have yet been performed in the mouse. In this respect it should also be noted that mice and rats are, apart from both being rodents, in fact rather different animals and separated in evolution by as many years as macaques and humans and by an increasing number of polymorphisms in nervous systemrelated genes (Dorus et al., 2004). Moreover, during vertebrate phylogeny the cerebellum has greatly expanded in parallel to the cerebral cortex, with a massive increase in cell number, especially in the cerebellar hemispheres and dentate nucleus, which correspond to the regions most prominently connected with the nonmotor cortical areas in primates (HerculanoHouzel, 2009; Strick et al., 2009). Thus, although the cerebellar modular organization is conserved throughout vertebrates (Voogd, 2011), it may be premature to infer that mice and rats share the same cerebello-cortical connectivity (Shmuelof and Krakauer, 2011) and that proof of a cerebellar contribution to cognitive or emotional processes in rats, let alone primates, also holds for mice. Accordingly, we must consider the evolutionary possibility that cerebellar involvement in cognitive functions appeared gradually during vertebrate phylogeny (Barton, 2012). 


\section{References}

Barton RA (2012) Embodied cognitive evolution and the cerebellum. Philos Trans R Soc Lond B Biol Sci 367:2097-2107.

Belmeguenai A, Hosy E, Bengtsson F, Pedroarena CM, Piochon C, Teuling E, He Q, Ohtsuki G, De Jeu MT, Elgersma Y, De Zeeuw CI, Jörntell H, Hansel C (2010) Intrinsic plasticity complements long-term potentiation in parallel fiber input gain control in cerebellar Purkinje cells. J Neurosci 30:13630-13643. CrossRef Medline

Boele HJ, Koekkoek SK, De Zeeuw CI (2010) Cerebellar and extracerebellar involvement in mouse eyeblink conditioning: the ACDC model. Front Cell Neurosci 3:19. CrossRef Medline

Buccafusco JJ (2009) Methods of behavior analysis in neuroscience, Ed 2. Boca Raton, FL: CRC.

Burguière E, Arleo A, Hojjati M, Elgersma Y, De Zeeuw CI, Berthoz A, RondiReig L (2005) Spatial navigation impairment in mice lacking cerebellar LTD: a motor adaptation deficit? Nat Neurosci 8:1292-1294. CrossRef Medline

Burguière E, Arabo A, Jarlier F, De Zeeuw CI, Rondi-Reig L (2010) Role of the cerebellar cortex in conditioned goal-directed behavior. J Neurosci 30:13265-13271. CrossRef Medline

Button KS, Ioannidis JP, Mokrysz C, Nosek BA, Flint J, Robinson ES, Munafò MR (2013) Power failure: why small sample size undermines the reliability of neuroscience. Nat Rev Neurosci 14:365-376. CrossRef Medline

Carter RM, Hofstotter C, Tsuchiya N, Koch C (2003) Working memory and fear conditioning. Proc Natl Acad Sci U S A 100:1399-1404. CrossRef Medline

Courchesne E (1997) Brainstem, cerebellar, and limbic neuroanatomical abnormalities in autism. Curr Opin Neurobiol 7:269-278. CrossRef Medline

Crawley JN (2007) What's wrong with my mouse: behavioral phenotyping of transgenic and knockout mice. New York: Wiley.

Critchley HD, Daly EM, Bullmore ET, Williams SC, Van Amelsvoort T, Robertson DM, Rowe A, Phillips M, McAlonan G, Howlin P, Murphy DG (2000) The functional neuroanatomy of social behaviour: changes in cerebral blood flow when people with autistic disorder process facial expressions. Brain 123:2203-2212. CrossRef Medline

De Zeeuw CI, Hansel C, Bian F, Koekkoek SK, van Alphen AM, Linden DJ, Oberdick J (1998) Expression of a protein kinase C inhibitor in Purkinje cells blocks cerebellar LTD and adaptation of the vestibulo-ocular reflex. Neuron 20:495-508. CrossRef Medline

De Zeeuw CI, Hoebeek FE, Bosman LW, Schonewille M, Witter L, Koekkoek SK (2011) Spatiotemporal firing patterns in the cerebellum. Nat Rev Neurosci 12:327-344. CrossRef Medline

Dorus S, Vallender EJ, Evans PD, Anderson JR, Gilbert SL, Mahowald M, Wyckoff GJ, Malcom CM, Lahn BT (2004) Accelerated evolution of nervous system genes in the origin of Homo sapiens. Cell 119:1027-1040. CrossRef Medline

Draski LJ, Nash DJ, Gerhardt GA (1994) CNS monoamine levels and motoric behaviors in the hotfoot ataxic mutant. Brain Res 645:69-77. CrossRef Medline

Elgersma Y, Fedorov NB, Ikonen S, Choi ES, Elgersma M, Carvalho OM, Giese KP, Silva AJ (2002) Inhibitory autophosphorylation of CaMKII controls PSD association, plasticity, and learning. Neuron 36:493-505. CrossRef Medline

Falls WA, Miserendino MJ, Davis M (1992) Extinction of fear-potentiated startle: blockade by infusion of an NMDA antagonist into the amygdala. J Neurosci 12:854-863. Medline

Galliano E, Gao Z, Schonewille M, Todorov B, Simons E, Pop AS, D’Angelo E, van den Maagdenberg AM, Hoebeek FE, De Zeeuw CI (2013) Silencing the majority of cerebellar granule cells uncovers their essential role in motor learning and consolidation. Cell Rep 3:1239-1251. CrossRef Medline

Gao Z, van Beugen BJ, De Zeeuw CI (2012) Distributed synergistic plasticity and cerebellar learning. Nat Rev Neurosci 13:619-635. CrossRef Medline

Garrard P, Martin NH, Giunti P, Cipolotti L (2008) Cognitive and social cognitive functioning in spinocerebellar ataxia: a preliminary characterization. J Neurol 255:398-405. CrossRef Medline

Glickstein M, Strata P, Voogd J (2009) Cerebellum: history. Neuroscience 162:549-559. CrossRef Medline

Han JH, Kushner SA, Yiu AP, Hsiang HL, Buch T, Waisman A, Bontempi B, Neve RL, Frankland PW, Josselyn SA (2009) Selective erasure of a fear memory. Science 323:1492-1496. CrossRef Medline
Herculano-Houzel S (2009) The human brain in numbers: a linearly scaled-up primate brain. Front Hum Neurosci 3:31. CrossRef Medline

Homberg JR (2012) Serotonergic modulation of conditioned fear. Scientifica 2012:821549. CrossRef

Ivarsson M, Svensson P, Hesslow G (2000) Contralateral cerebellar involvement in conditioned eyeblink responses. Prog Brain Res 124: 309-316. CrossRef Medline

Jones A, Paterlini M, Wisden W, Merlo D (2000) Transgenic methods for directing gene expression to specific neuronal types: cerebellar granule cells. Prog Brain Res 124:69-80. CrossRef Medline

Kushner SA, Elgersma Y, Murphy GG, Jaarsma D, van Woerden GM, Hoijati MR, Cui Y, LeBoutillier JC, Marrone DF, Choi ES, De Zeeuw CI, Petit TL, Pozzo-Miller L, Silva AJ (2005) Modulation of presynaptic plasticity and learning by the H-ras/extracellular signal-regulated kinase/synapsin I signaling pathway. J Neurosci 25:9721-9734. CrossRef Medline

Lalonde R, Strazielle C (2003) The effects of cerebellar damage on maze learning in animals. Cerebellum 2:300-309. CrossRef Medline

Leggio MG, Molinari M, Neri P, Graziano A, Mandolesi L, Petrosini L (2000) Representation of actions in rats: the role of cerebellum in learning spatial performances by observation. Proc Natl Acad Sci U S A 97:2320-2325. CrossRef Medline

Liu Y, Formisano L, Savtchouk I, Takayasu Y, Szabó G, Zukin RS, Liu SJ (2010) A single fear-inducing stimulus induces a transcriptiondependent switch in synaptic AMPAR phenotype. Nat Neurosci 13:223231. CrossRef Medline

Oberdick J (1994) Evidence for a genetically encoded map of functional development in the cerebellum. Histochemistry 102:1-14. CrossRef Medline

Pape HC, Pare D (2010) Plastic synaptic networks of the amygdala for the acquisition, expression, and extinction of conditioned fear. Physiol Rev 90:419-463. CrossRef Medline

Petrosini L, Leggio MG, Molinari M (1998) The cerebellum in the spatial problem solving: a costar or a guest star? Prog Neurobiol 56:191-210. CrossRef Medline

Ramnani N (2006) The primate cortico-cerebellar system: anatomy and function. Nat Rev Neurosci 7:511-522. CrossRef Medline

Rochefort C, Arabo A, André M, Poucet B, Save E, Rondi-Reig L (2011) Cerebellum shapes hippocampal spatial code. Science 334:385-389. CrossRef Medline

Ruediger S, Vittori C, Bednarek E, Genoud C, Strata P, Sacchetti B, Caroni P (2011) Learning-related feedforward inhibitory connectivity growth required for memory precision. Nature 473:514-518. CrossRef Medline

Sacchetti B, Scelfo B, Tempia F, Strata P (2004) Long-term synaptic changes induced in the cerebellar cortex by fear conditioning. Neuron 42:973982. CrossRef Medline

Scelfo B, Sacchetti B, Strata P (2008) Learning-related long-term potentiation of inhibitory synapses in the cerebellar cortex. Proc Natl Acad Sci U S A 105:769-774. CrossRef Medline

Schmahmann JD (2010) The role of the cerebellum in cognition and emotion: personal reflections since 1982 on the dysmetria of thought hypothesis, and its historical evolution from theory to therapy. Neuropsychol Rev 20:236-260. CrossRef Medline

Schmahmann JD, Sherman JC (1997) Cerebellar cognitive affective syndrome. International review of neurobiology 41:433-440. CrossRef Medline

Schonewille M, Belmeguenai A, Koekkoek SK, Houtman SH, Boele HJ, van Beugen BJ, Gao Z, Badura A, Ohtsuki G, Amerika WE, Hosy E, Hoebeek FE, Elgersma Y, Hansel C, De Zeeuw CI (2010) Purkinje cell-specific knockout of the protein phosphatase PP2B impairs potentiation and cerebellar motor learning. Neuron 67:618-628. CrossRef Medline

Schraa-Tam CK, Rietdijk WJ, Verbeke WJ, Dietvorst RC, van den Berg WE, Bagozzi RP, De Zeeuw CI (2012) fMRI activities in the emotional cerebellum: a preference for negative stimuli and goal-directed behavior. Cerebellum 11:233-245. CrossRef Medline

Seja P, Schonewille M, Spitzmaul G, Badura A, Klein I, Rudhard Y, Wisden W, Hübner CA, De Zeeuw CI, Jentsch TJ (2012) Raising cytosolic Cl- in cerebellar granule cells affects their excitability and vestibulo-ocular learning. EMBO J 31:1217-1230. CrossRef Medline

Shiflett MW, Balleine BW (2011) Contributions of ERK signaling in the striatum to instrumental learning and performance. Behav Brain Res 218: 240-247. CrossRef Medline

Shinoda Y, Kano M, Futami T (1985) Synaptic organization of the 
cerebello-thalamo-cerebral pathway in the cat: I. Projection of individual cerebellar nuclei to single pyramidal tract neurons in areas 4 and 6 . Neurosci Res 2:133-156. CrossRef Medline

Shmuelof L, Krakauer JW (2011) Are we ready for a natural history of motor learning? Neuron 72:469-476. CrossRef Medline

Spitzer B, Gloel M, Schmidt TT, Blankenburg F (2013) Working memory coding of analog stimulus properties in the human prefrontal cortex. Cereb Cortex Advance online publication March 31, 2013. PMID: 23547134. doi:10.1093/cercor/ bht084. CrossRef Medline

Strick PL, Dum RP, Fiez JA (2009) Cerebellum and nonmotor function. Annu Rev Neurosci 32:413-434. CrossRef Medline

Teune TM, van der Burg J, van der Moer J, Voogd J, Ruigrok TJ (2000) Topography of cerebellar nuclear projections to the brainstem in the rat. Prog Brain Res 124:141-172. CrossRef Medline

Timmann D, Drepper J, Frings M, Maschke M, Richter S, Gerwig M, Kolb FP (2010) The human cerebellum contributes to motor, emotional and cognitive associative learning: a review. Cortex 46:845-857. CrossRef Medline

Tronson NC, Schrick C, Fischer A, Sananbenesi F, Pagès G, Pouysségur J, Radulovic J (2008) Regulatory mechanisms of fear extinction and depression-like behavior. Neuropsychopharmacology 33:1570-1583. CrossRef Medline

Tsai PT, Hull C, Chu Y, Greene-Colozzi E, Sadowski AR, Leech JM, Steinberg J, Crawley JN, Regehr WG, Sahin M (2012) Autistic-like behaviour and cerebellar dysfunction in Purkinje cell Tsc1 mutant mice. Nature 488: 647-651. CrossRef Medline

Voogd J (2011) Cerebellar zones: a personal history. Cerebellum 10: 334-350. CrossRef Medline

Wulff P, Schonewille M, Renzi M, Viltono L, Sassoè-Pognetto M, Badura A, Gao Z, Hoebeek FE, van Dorp S, Wisden W, Farrant M, De Zeeuw CI (2009) Synaptic inhibition of Purkinje cells mediates consolidation of vestibulo-cerebellar motor learning. Nat Neurosci 12:10421049. CrossRef Medline

Zhu L, Scelfo B, Hartell NA, Strata P, Sacchetti B (2007) The effects of fear conditioning on cerebellar LTP and LTD. Eur J Neurosci 26:219227. CrossRef Medline

Zobel S, Hummel T, Ilgner J, Finkelmeyer A, Habel U, Timmann D, Schulz JB, Kronenbuerger M (2010) Involvement of the human ventrolateral thalamus in olfaction. J Neurol 257:2037-2043. CrossRef Medline 